\title{
Review Article \\ Palliatives for Low Velocity Impact Damage in Composite Laminates
}

\author{
Mubarak Ali, ${ }^{1}$ S. C. Joshi, ${ }^{2}$ and Mohamed Thariq Hameed Sultan ${ }^{3,4}$ \\ ${ }^{1}$ Department of Mechanical Engineering, National Institute of Technology Calicut (NITC), Kerala 673601, India \\ ${ }^{2}$ School of Mechanical and Aerospace Engineering, Nanyang Technological University, N3-B3a-01, \\ 50 Nanyang Avenue, Singapore 639798 \\ ${ }^{3}$ Aerospace Manufacturing Research Center (AMRC), Faculty of Engineering, Universiti Putra Malaysia (UPM), \\ 43400 Serdang, Selangor Darul Ehsan, Malaysia \\ ${ }^{4}$ Laboratory of Biocomposite Technology, Institute of Tropical Forestry and Forest Products (INTROP), \\ Universiti Putra Malaysia (UPM), 43400 Serdang, Selangor Darul Ehsan, Malaysia
}

Correspondence should be addressed to Mubarak Ali; muba0001@e.ntu.edu.sg

Received 2 March 2017; Revised 17 July 2017; Accepted 27 July 2017; Published 11 September 2017

Academic Editor: Belal F. Yousif

Copyright (C) 2017 Mubarak Ali et al. This is an open access article distributed under the Creative Commons Attribution License, which permits unrestricted use, distribution, and reproduction in any medium, provided the original work is properly cited.

\begin{abstract}
Fibre reinforced polymer laminated composites are susceptible to impact damage during manufacture, normal operation, maintenance, and/or other stages of their life cycle. Initiation and growth of such damage lead to dramatic loss in the structural integrity and strength of laminates. This damage is generally difficult to detect and repair. This makes it important to find a preventive solution. There has been abundance of research dealing with the impact damage evolution of composite laminates and methods to mitigate and alleviate the damage initiation and growth. This article presents a comprehensive review of different strategies dealing with development of new composite materials investigated by several research groups that can be used to mitigate the low velocity impact damage in laminated composites. Hybrid composites, composites with tough thermoplastic resins, modified matrices, surface modification of fibres, translaminar reinforcements, and interlaminar modifications such as interleaving, short fibre reinforcement, and particle based interlayer are discussed in this article. A critical evaluation of various techniques capable of enhancing impact performance of laminated composites and future directions in this research field are presented in this article.
\end{abstract}

\section{Introduction}

Materials have coexisted and connected with mankind virtually from the very beginning of man's existence in satisfying variety of needs. Almost every facet of human life has been influenced by materials to varying degrees. Only the approach of engineering and fabricating materials has changed over time. Advanced materials and their understanding have been continuously evolving leading to new materials and technologies at a faster pace. There are more than 50000 different grades of materials available for design engineers for variety of applications. These materials extend from simple monolithic materials such as cast iron, titanium, and copper to very sophisticated and high performance materials such as composites and ceramics. Understanding of science of materials and technologies for their manipulation led to synthesis and development of new materials with fascinating properties and applications, particularly in 20th century. Second half of 20th century has witnessed an extraordinary growth and advancement of technology of composite materials.

Early industrial applications of high performance composite materials were during world war II with military marine based applications but now the products fabricated using these materials are utilised by a variety of industries, like marine, automotive, aerospace, sporting goods, boating, orthopaedics, and more [1]. Two important advancements in the technological world have significantly affected the fulfilment of demands created by aircraft and military sectors: one is the progress in composites technology and the other is computational mechanics. Complex design and fabrication issues of composites are resolved by extraordinary 
computational powers as well as advancements in both CAD and CAM [2].

Composite material is constructed by the combination of two or more different materials to induce incomparable blend of properties. This description is more general and can include all classes of materials such as metallic, ceramic, polymers, wood, and other minerals. Wood is a natural composite because it is normally made of two separate constituents: stiff and strong fibres (cellulose) enveloped by a supporting structure of softer tissue (lignin) forming cell walls. Some of the other examples of composite materials that exist in nature are bones which have collagen (matrix) and mineral crystals (reinforcing fibres), shells of invertebrates, such as oysters, snails, husks, silky threads spun by spiders, and straw mixed with clay for construction for many centuries.

There are several types of classification of composite materials. A more classical method of classification of composites is based on the type of reinforcements. Two broad classes of composites are (1) fibrous and (2) particulate composites [7]. Each class of composites is further divided into subcategories. Fibrous composites are further subdivided into continuous fibre composites and discontinuous fibre composites (chopped fibres/whiskers). Particulate composites composed of particles incorporated in a matrix material. Particulate composites may be further subdivided into flake and filled/skeletal composites depending upon size and shape of suspended particles. A filled/skeletal composite is composed of a continuous skeletal matrix filled by a second material, for example, a honeycomb core filled with an insulating material [7].

Fibre reinforced laminates differ from natural materials in that constituent materials (reinforcing fibres and matrix materials usually polymer/plastics) are separate phases mechanically and have different molecular structures. Fibres are the main load bearing constituents and matrix successfully transfers load to fibres. Carbon and glass fibres are the most extensively used fibres in laminated composites for structural applications. Carbon fibres have high strength and stiffness while glass fibres have comparatively lower stiffness and strength but with high strain to failure than the carbon fibres. Properties of Kevlar fibres prevail between glass and carbon fibres [8]. Kevlar fibres are light weight and flexible with a unique combination of high toughness, high modulus, and thermal stability. Matrix materials give shape to composites and protect fibres against environment and chemical attack. Both thermosetting and thermoplastic matrices are used in laminated composites with thermosets offering greater thermal and dimensional stability, higher rigidity, and chemical resistance. Epoxy resin is widely used as thermoset matrix in fibre reinforced composites because of its remarkable mechanical properties, low shrinkage, strong adhesion, chemical stability, and dimensional stability.

\section{Properties of Laminated Composite Materials}

In comparison with traditional structural materials such as steel and aluminium, these composites have greater specific strength and specific stiffness, hence making structural parts lighter. These materials are intrinsically heterogeneous because of the presence of two or more distinct materials. Furthermore these materials exhibit significant anisotropy. While anisotropy properties enable optimization of composites parts to directional loads and design flexibility, they also lead to the complexity in the assessment, study of damage mechanisms, and their structural response.

Another notable feature of polymer based laminated composite materials is the nonlinear material behaviour under mechanical loads primarily because of nonlinear matrix and progressive damage. They exhibit time dependent nonlinear response to the load. Another peculiar characteristic is the presence of varying degrees of amorphous phases in the polymer matrices. This kind of nonequilibrium state of polymer composites makes them significantly sensitive to environmental factors such as temperature and exposure to electrical fields, gases, liquids, and radiation. Structural loads, both static and dynamic, may interact with these environmental factors and lead to synergistic accelerated degradation phenomenon $[1,9,10]$. These composites are generally highly corrosive resistant materials compared to metals because of the polymer matrix surrounding the fibres and protecting the fibres from environment.

\section{Impact Damage in Composite Laminates}

Fibre-matrix interface and interlaminar interfaces in composite laminates constitute the weakest regions for debonding and delamination to initiate. This problem is worsened by other structural features like sharp bends needed in stiffening members and discontinuous plies to produce thickness changes. One of the primary concerns in composite materials has been the susceptibility to impact damage. This kind of damage leads to large reduction in strength and also the damage in the material remains insidious for visual detection. Low plastic deformation of advanced composite materials leads to vulnerability of such structures to different failure modes such as fibre breakage, delamination, and matrix cracking under impact events.

Impact or high strain rate loads are anticipated in many real time applications of composite materials. Application of a composite material for such situations therefore is decided not only by its static strength considerations but also by its energy absorbing properties and impact behaviour. Sometimes an attempt to improve the in-plane mechanical properties results in a reduction of impact performance. Therefore, secure and efficient design of structures calls for a thorough cognisance of the impact behaviour of composites, so that new composites may be formed which possess both good impact properties and good in-plane properties [11].

3.1. Causes of Impact Damage. There are several sources of impact damage of the composite materials. Some of them are listed below.

(1) Dropping of tools during maintenance or repair on the composite structure

(2) Hailstone impact

(3) Debris or foreign object impact 
(4) Impact or jolts even before the assembly of the structure

(5) Bird strike on the aircraft

(6) Tyre debris from burst tyres

(7) Accidental collision with other handling equipment

(8) Walking on a structure

(9) Rotor burst, blade loss, and engine debris

(10) Lightning strike shock waves

(11) Meteorites

(12) Hard landings

(13) Wheel threats

(14) Crash and ditching of the structure

(15) Bullet in ballistic impact

Bird strike impact has been increasing due to increasing air traffic and the change in the migration pattern of birds. At least one flight out of 2000 is estimated to encounter bird strike events. Since 1912 in civil aviation, bird strikes have claimed over 50 planes and more than 223 lives [12]. Bird Strike Committee reports that the damage losses due to damage in composite structures of US civil and military aviation have reached over $\$ 600$ million because of bird strikes. The global death toll from wildlife strikes since 1988 stands at 195 . Additionally, a number of countries have seen a huge rise in the population of large flocking birds [13].

Runway debris can damage composite structures and poses a serious threat to their integrity. Debris may be gravel or even unwanted small metallic objects from the runway. While the threat from impacts to aluminium parts is not high, aircraft with composite skins are in serious jeopardy. Hail impacts present even greater risks to aircraft structures. Impacts from hailstones, which have diameters over $10 \mathrm{~cm}$, are extensive, repetitive, and incessant. They often occur at cruise speeds $(800 \mathrm{~km} / \mathrm{hr}$ or $222 \mathrm{~m} / \mathrm{s})$. Even aluminium aircraft are endangered by these kinds of impact sequences [14]. One aspect that is yet to be examined in detail is the influence of multiple impacts, which refers to repetitive impacts occurring in sequence at locations near each other. In a hailstorm, a fast moving vehicle is subject to these kinds of repetitive impacts. Effect of two or more closely located simultaneous impacts is also not properly understood, even though the delamination process could be considerably intensified because of it.

A highly significant factor in aircraft vulnerability is the Hydrodynamic Ram (HRAM) phenomenon. Of all vulnerable components, the wing area is exposed the most. The HRAM occurs when the fuel tanks are penetrated by a highenergy object. Aircraft structures can also be impacted by projectiles such as small and medium calibre bullets and fragments resulting from a blast, which may hit the fuel tank of an airplane or helicopter and induce HRAM effects. Aircraft that have lightweight designs are especially vulnerable to HRAM because the integral fuel tanks cannot be made more structurally resistant by increasing the toughness of the airframe [15].

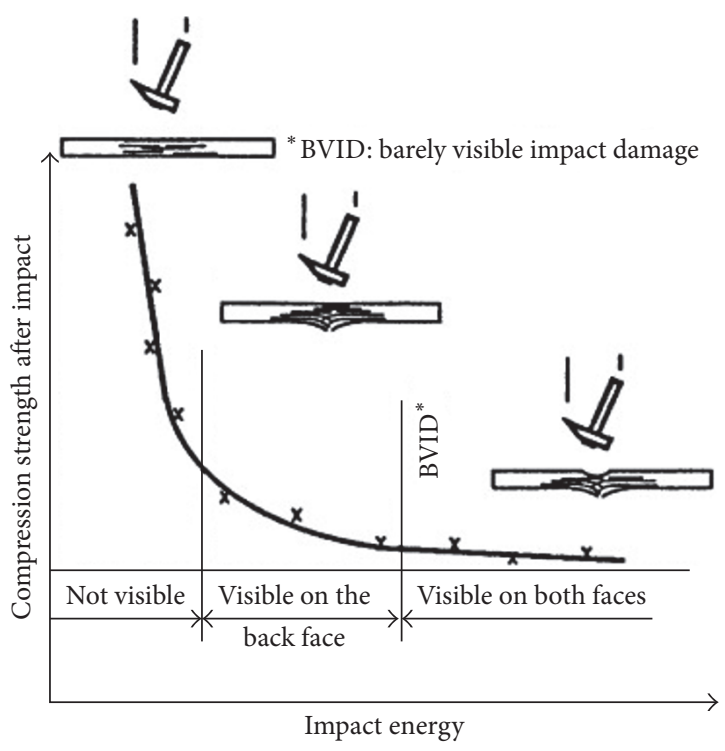

FIGURE 1: Effect of BVID on compression after impact strength [3].

3.2. Types of Impact Damage. Impact damage resulting from a variety of causes discussed so far are categorized into three kinds, namely, low velocity, ballistic, and hypervelocity impacts. A leading problem in the use of laminated composite materials is the impact which occurs when blunt objects impact at low velocities. This type of impact leads to internal damage called barely visible impact damage (BVID) which goes unnoticed as it frequently forms deep within the structure or in the back face [16]. This damage severely threatens the integrity and residual strength $[17,18]$ of the structure (refer to Figure 1).

Due to entirely different microstructural morphology and fabrication between composites and metals, impact response of composite structures differs significantly from metallic structures $[8,19,20]$. Visible damage on the surface will be created due to impact on metallic structures, whereas damage would be concealed inside composite laminates, for low velocity impact in particular [11]. In metallic structures, large amount of energy can be absorbed due to its ductile nature and the effect of impact on the residual load carrying capacity of the metals is usually small and can be predicted [19]. Small surface dent does not warrant much attention in metals since it merely increases work hardening locally. Most composites are brittle and so they can only absorb energy in elastic deformation and through damage mechanisms and not via plastic deformation [21-24]. For laminated composites though, even a slightly apparent dent can induce separation of interior plies (delamination). Low velocity impact does not initially result in catastrophic failure of the laminate but it is the major cause of delamination onset $[25,26]$. Delaminations may increase with more impacts or further loading during service. Since the carbon fibre composites are opaque, neither the damage nor the growth can be seen. Final catastrophic fracture could occur without the preceding damage being noticed [16].

Impact events that occur at low velocity can be treated as quasi-static $[27,28]$. These are normally nonpenetrating 
and their upper limit can vary from 1 to $10 \mathrm{~m} / \mathrm{s}[19,27,28]$. Those impacts for which the propagation of the stress wave through the specimen is not considerable are also categorized as having low velocity $[29,30]$. Contact between the projectile and the target is followed by propagation of Rayleigh waves, a compressive wave, and a shear wave. Compressive and shear waves reach the back face and reflect back. After many reflections through the thickness of the laminate, the plate motion is established. Impacts for which damage is introduced after plate motion is established are called low velocity impacts [11]. For most common epoxy matrix composites, at impact velocities between 10 and $20 \mathrm{~m} / \mathrm{s}$, the transition of impact event to a stress wave dominated mode happens $[29,30]$. Low velocity impact was also classed as type of impact in which delamination and matrix cracking are the primary damage modes $[31,32]$. The most frequent types of impact events occurring on composite structures are low velocity impacts.

The low velocity impact response of woven fabric composite laminates has been extensively treated in the literature by experimental research works, analytical formulations, and numerical implementations. Abrate [33] presents an overview of mathematical models used for the analysis of the dynamics of impact. The available mathematical models were classified into four categories: spring-mass models, energy-balance models, complete models, and an impact on infinite plate model. A procedure is presented in order to determine the expected type of impact and to select an appropriate model [33]. Naik et al. [34] studied the behaviour of woven fabric composite plates under transverse low velocity impact employing an analytical model based on a modified Hertz law and a 3D numerical model. The in-plane failure behaviour of the composites has been evaluated by means of failure function based on the Tsai-Hill quadratic failure criterion [34]. Johnson et al. [35] presented a materials failure model for composites with fabric reinforcement under impact loading, which included both intraply damage and plasticity based on continuum damage mechanics approach and interply delamination. Iannucci and Willows [36] presented an energy based damage mechanics model and interface modelling technique for woven carbon composites under high strain dynamic loading employing an explicit FE code. Reyes and Sharma [37] studied experimentally and numerically a low velocity impact damage behaviour of woven thermoplastic laminates under various levels of impact energies. A simple energy-balance model was used to predict the maximum impact force and deflection of the laminates.

It has been identified that there are at least three dominant failure mechanisms taking place in the composite laminates when subjected to impact loading. These are interlaminar fracture (or delamination), matrix cracking due to transverse shear, fibre-matrix debonding, and translaminar (fibre) fracture [38-44]. The first two mechanisms are sensitive to the properties of the matrix materials and the last to the fibre performance, especially the failure strain. Depending on the properties of the constituents, choice of fibre and matrix types, the fracture process can be a very complex combination of these energy absorption mechanisms [45, 46]. Delamination as a subcritical mode of damage is indirectly responsible for the final failure of the structures $[25,26]$. Because of the synergistic multidamage mechanisms experienced by the laminates under impact, impact damage evaluation still largely relies on experimental results rather than numerical simulations and analytical models [47].

Many studies have so far been devoted to the damage prediction of low velocity impact on composite laminates. Hou et al. $[48,49]$ studied the damage initiation and evolution based on fibre failure, matrix cracking, matrix crushing, and delamination. A simple empirical formula to model delamination and size and shape of the delamination was predicted which did not agree well with the experimental results. Li et al. [50, 51] used the Reissner-Mindlin plate model to simulate the failure process of long fibre reinforced laminate under low speed impact. Xu et al. [52,53] simulated four types of damage (fibre tensile failure, fibre compressive failure, matrix tensile failure, and matrix compressive) using stiffness degeneration. They proposed an improved failure criterion and a progressive failure model.

3.3. Parameters Affecting Impact Damage. Damage mechanisms and energy absorption of composite materials have greater complexity than metallic structures. Damage resistance of composite laminates under impact is influenced by a number of factors such as total number of layers, impactor geometry [54], impactor initial energy, impact velocity [55], interlaminar properties and bonding strength, ply layup [56-60], and matrix and fibre properties. The interactions between these factors has been elaborated on in [19]. Due to the influence of material properties on overall structure's stiffness and contact stiffness, dynamic response is also appreciably affected. Both the initiation and propagation of impact damage depend on properties of fibre, matrix, and the surface modification of fibre. Since the boundary conditions, the size [60-63], and thickness $[60,63,64]$ control the stiffness of the target, they all affect the impact dynamics. The study of size effects on impact loaded composite laminates was focused on analytical scaling laws and parameters [61, 62, 65]. Smaller specimens were always stronger than larger ones [61] and delamination size was found to be consistent with the size effect [65]. Experimental results showed that in-plane dimensional effect was not as significant as thickness effect [63].

Other parameters that influence impact events are the characteristics of the projectile such as its shape, elastic properties, density, and incidence angle. The most common impactor shape studied has been hemispherical [66-70] and other impactor shapes such as flat $[67-69,71]$, conical [67, 68, 70], ogival [70], and semicylindrical [67] ones have also been investigated. Flat and hemispherical impactors produced similar failure mechanisms and energy dissipation levels [67]. The semicylindrical impactor produced a vertically propagating crack [67] and use of conical impactor resulted in lowest dissipated impact energy and localised damage with lower delamination areas $[67,68]$. The change in the impactor shape resulted in a change in failure mode. Matrix cracking followed by fibre fracture has been the predominant failure mode under hemispherical impactor [69] whereas ply shear-out was found to be the dominant failure mode with the flat impactor [69, 71]. Researchers have 
also observed the effects of stitching [72-74], ageing [75-77], and environmental conditions [78-81] on impact damage. Most composite structures will be under some level of stress when impacted. The nature and magnitude of the preload strongly influence the response of the composite laminate under impact [82-84], shape, orientation, and size of the damage zone $[83,85]$. Impact specimens subjected to shear loading exhibit the largest increase in the damage area when compared to unstressed plates [85].

\section{Residual Properties of Impact Damaged Laminates}

Impact damage substantially reduces the structural integrity and residual strength of laminated composite materials, resulting in the growth of damage and final fracture. The term damage tolerance refers to a structure's ability to perform required function after an impact damage [86]. Even BVID (barely visible impact damage) can lead to $50 \%$ reduction in strength of the structure. Residual strength in compression, tension, and flexure will be deteriorated depending on the predominant damage mode. Even vibration and fatigue characteristics will also be affected by the impact damage. Experimental studies show that fibre strength and strain to failure have a considerable consequence on the tensile strength of damaged as well as undamaged laminates, while the material properties of the matrix have a relatively insignificant effect [11]. Thus, fibre damage is the critical damage mode influencing tensile residual strength of the composite materials. Cross-ply laminates have a higher deterioration in residual tensile strength than the angle-ply laminates [87]. A method of prediction of residual tensile strength was presented based on the premises that the stress concentration associated with the constraint of the undamaged material around the impacted region dominates the remaining strength calculation and that the physical parameter that enters the model should be the size and shape of the damage region [88]. Another prediction model for the tensile residual strength after impact was proposed, in which the damaged area is replaced with an equivalent hole notch [89].

The residual property which is most acutely affected is the compression after impact strength of the composite laminates. Delaminations induced by impact often terminate in substantial reduction in compressive properties [90]. Toughness of the matrix resin is the major parameter influencing the compression after impact (CAI) performance in quasi-isotropic laminates rather than fibre strength and stiffness [90]. Stacking sequence of the laminate was found to affect the CAI performance [91]. Cross-ply laminate showed the least damage tolerance and exhibited higher instability when subjected to compressive loading [92]. Low modulus copolyamide web interleaves resulted in an increase in damage area and minor changes to CAI strength. Higher shear modulus polyethylene interleaves resulted in a significant decrease in the damage area at various impact energies, with CAI strength improved compared to noninterleaved laminates [93].

Both the residual flexural strength and flexural stiffness are affected by impact damage with flexural strength being highly sensitive to localised impact than flexural modulus $[94,95]$. Under single impact loading the composites suffer a slight reduction in residual flexural strength but a large reduction in interlaminar shear strength [96]. Large degradation in the postimpact flexural strength was observed in GFRP laminates subjected to repeated impacts which is attributed to the fracture of the glass fibres [96]. Investigations of damage evolution under low velocity impact revealed that there existed a critical impact energy for initial damage, standing for the change in the damage mode and dividing the postimpact flexural properties variation into two linear parts [95]. There has been considerable research attention on the cyclic loading of impact damaged composite laminates [53, 97-99]. Doubling the incident impact energy from 5 to $10 \mathrm{~J}$ was found to reduce the residual fatigue life at a given stress by approximately one decade [100]. Significant reduction of compression fatigue life was observed in impact damaged carbon/epoxy laminates and compressive fatigue characteristics were identified to be strain rate dependent [101]. During spectrum loading fatigue tests on carbon fibre composite coupons, it was found that removing the low load cycles from a spectrum fatigue test did not affect the fatigue life and therefore that only the high load cycles were propagating damage [102]. Fatigue tests on CFRP at varying load ratios revealed that greater reduction in fatigue life was found when the compressive component of the cycle load is larger [103].

\section{Palliatives for Impact Damage}

The current philosophy to handle impact damage related problems is as follows:

(1) To tolerate moderately severe impacts, the structure is designed with alternative load paths. This is accomplished by designing the structure as a framework of stiffening members or as boxes.

(2) To sustain barely visible impact damage (BVID) at the highest load and for the entire duration, the design allowable strength is reduced adequately so as to have no degradation in performance.

(3) Damage that crosses BVID level (visible damage) may bring down immediate performance and must be promptly repaired. An improved design that has damage tolerance against impact is drawn up to ensure the basic safety of the structures with damage.

(4) Structure might not tolerate very severe impact. Designing impact resistant structures have been carried out [2].

(5) New composite materials with increased impact resistance are developed.

Developing improved and tough composite materials to lessen severity of impact damage has been a major challenge for the researchers.

5.1. Hybrid Composites. Fibres are important load bearing constituent materials during impact in the composites. Laminates reinforced with Kevlar and S-glass fibres showed five times higher Charpy impact resistance than Modmor II 
carbon fibre reinforced composite [104]. This low impact resistance of carbon fibre composites was due to extremely brittle nature of the carbon fibres, which fail catastrophically at peak impact load. Kevlar fibre/epoxy matrix composites showed exceptional energy absorbing capability when compared to carbon fibre/epoxy composites [8]. Concept of hybrid composites materials was developed to utilise the potential of the Kevlar and glass fibres for improving the impact performance of CFRP. In this method, the impact resistance of high modulus fibre laminates is enhanced by adding to them a small percentage of a low modulus fibre, which results in higher impact performance. This incorporation is called hybridization. Generally E-glass or Kevlar fibres are used frequently for this purpose because these fibres store more energy elastically than carbon fibres. Besides improving the impact performance, incorporation of glass fibres reduces cost of the composites [10]. Combination of two or more fibres in a common matrix produces hybrid composites, which offer a range of properties, which are not achievable with just one type of reinforcement. Hybrid material retains benefits of its original constituents, while often allowing cost to be reduced [105].

Two types of hybrid composites can be distinguished based on the fibre arrangement pattern: hybrid intraply and hybrid interply composites. In hybrid interply (interlaminated) composites, two or more homogeneous layers of fibre reinforcement are stacked layerwise with one type of fibre in single layer, and then different fibre plies are dispersed throughout the laminate, while in hybrid intraply (intermingled) laminates two or more different fibre tows are combined in a single layer of reinforcement with no intentional concentration of either type of fibres throughout the resin $[105,106]$. The volume ratio and stacking sequence of different components in the hybrid material strongly influence the mechanical properties of hybrid composites. A number of research groups have studied the performance of interply hybrid composites [104, 106-113] and intraply hybrid composites [105, 114-117]. Hybrid intraply composites showed superior impact performance possibly due to superior efficiency in impeding the propagation of the cracks when compared to homogeneous or interply hybrid composites [115].

But this hybridization technique has the complication of mismatch of elastic moduli between different species of fibres and hence subsequent problem of higher complexity in the design of such laminates [8]. Moreover, obtaining a uniform blend in fabrication of intraply hybrid composites is practically difficult. In interply hybrids, the layup has to be exclusively symmetric with respect to the neutral axis; otherwise, temperature changes would lead to bendingstretching coupling and cause undesirable warping [10]. Moreover, hybridization will not improve the resistance to delaminations or matrix cracking, though it has its influence on fibre fracture.

5.2. Composites with Tough Thermoplastic Resins. Matrix in the composite materials performs vital functions: protecting the fibre reinforcement from damage, transferring loads to the fibres, and alignment/stabilisation of the fibres. Investigations towards improvement of matrix properties by effectively utilising tough thermoplastic resins to mitigate the impact damage $[118,119]$ have been carried out. Thermoplastic matrix such as poly(ether ether ketone), PEEK $[118,120]$ can improve fracture toughness by an order of magnitude over thermoset matrices. Further thermoplastic matrices will have higher strain to failure and ductility, which enhance the performance under impact loading.

Nylon thermoplastic matrix with carbon fibre in laminates exhibit higher fracture toughness and high elongation in addition to the advantages of processing and recycling [121, 122]. Other thermoplastic matrices which have the potential to improve impact properties are PEI (polyetherimide) and PPS (polyphenylene sulfide) [118, 123]. Fatigue properties of thermoplastic matrix composites were studied by numerous researchers [124-127] and found to have inferior fatigue performance compared to epoxy laminates $[124,125]$. Moreover thermoplastic resins lead to low modulus, low compressive strength, low chemical resistance, degraded thermal stability, and poor fibre-matrix interfacial bonding which has highly limited the usage of thermoplastic composites [120].

\subsection{Composites with Modified Matrix Material}

5.3.1. Rubber Modified Epoxy Matrices. Improving the impact performance of composite laminates by modifying the epoxy matrix material with rubber [128-130] has been studied. Such toughened composite materials absorb inelastic energy when subjected to low velocity impact loads [128]. Carboxylterminated CTBN rubber in liquid form was mixed with epoxy resin before the hand layup. The CTBN rubber modified matrix reduced the fracture toughness (impact) of the resulting composite compared with that of the unmodified composite at above ambient temperature [129], whereas the R curve (crack growth resistance curve) was superior to that of the control samples. Improvements in impact properties were also reported by carbon fibre reinforced composites, which had CNBR (acrylonitrile butadiene rubber, submicron crosslinked) modified epoxy matrix [131-133].

5.3.2. Epoxy Matrix Modified with Rigid Inorganic Fillers. Different types of inorganic fillers such as glass beads, silica, alumina, barium titanate, and aluminium hydroxide have also been considered for the improvement of impact toughness of the epoxy resins [134, 135]. Epoxy modified with rigid inorganic fillers such as short $\mathrm{Al}_{2} \mathrm{O}_{3}$ fibre and $\mathrm{Al}_{2} \mathrm{O}_{3}$ powder [129] have been studied. Without the rubber phase, however, adding rigid fillers to the matrix does not show noticeable resistance to crack growth. While rigid fillers induce brittleness in the resin, rubber plasticises it. The presence of both rubber and rigid fillers in the matrix leads to a counteractive effect, leading to enhanced deformation (nonlinear) of the matrix and other additional mechanisms of toughening by rigid fillers. Therefore, it is not useful to add rigid fillers without rubber phase because of embrittling effects [129].

5.3.3. CNT-Filled and Nanofilled Epoxy Composites. Recently, many research groups have focused their studies on nanofillers such as carbon nanofillers, carbon nanotubes 


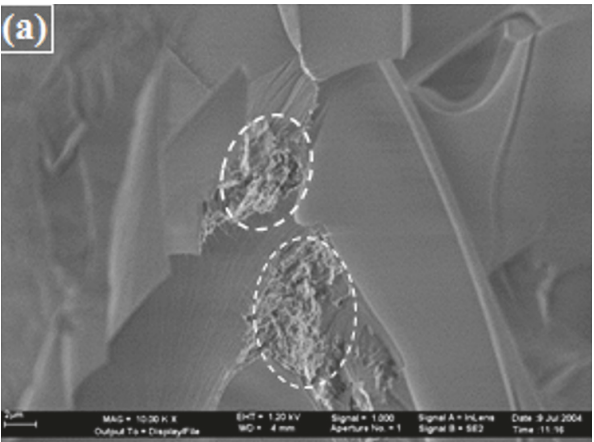

(a)

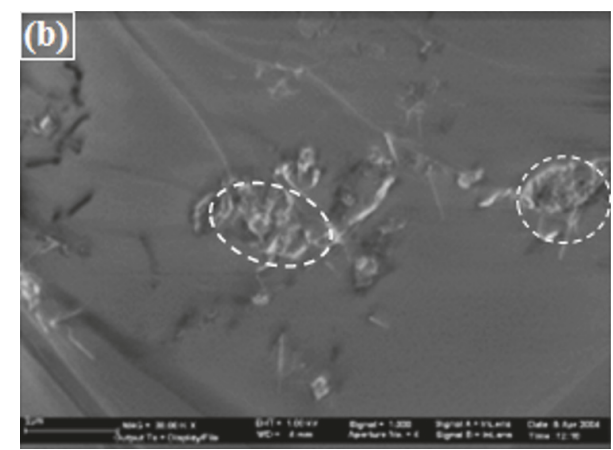

(b)

FIgURE 2: Agglomerates of CNTs observed in GFRP laminates [4].

(CNTs), nanoclays, and other nanoparticles to improve the mechanical properties of polymer based composites. CNTs [136], nanoscale $\mathrm{Al}_{2} \mathrm{O}_{3}$ particles [137], nanoscale $\mathrm{TiO}_{2}$ [138], silica nanoparticles [139], halloysite clay nanotubes [140], and nanoclay filled epoxy composites [141-143] have been recently investigated to improve the epoxy matrix properties. These nanoparticles/fillers have the ability to reinforce the matrix at the nanoscale. CNTs are found to be useful in inducing fibre bridging mechanisms because of their high specific area and aspect ratio with the combination of high longitudinal modulus which has the potential to improve fracture properties [136]. These methods are in their early stages and issues like agglomeration of nanoclay and CNTs because of inadequate uniformity of distribution in the matrix which becomes the potential site of crack initiation and stress concentration need to be resolved [136, 142, 144]. Figure 2 presents the SEM images demonstrating the CNT agglomerates in GFRP laminates with DWCNT modified epoxy matrix fabricated by RTM technique [4].

Brittle fibre hinders plastic zones of crack-tip to matrix rich narrow interply regions thus limiting the advantage of the tougher matrices. Hence comprehensive improvements in the properties of the composite are not expected by modifying the pure matrix resin [19]. Additionally, the processing of tougher and stronger matrix materials is also difficult and their usage is limited by cost.

5.4. Interleaving. Interleaving is the incorporation of tough interlayers between selected plies which improves the impact resistance substantially [145]. Development of interleaving materials which can remain as thin separate layers during cocuring with the matrix material is an important consideration in this concept. Interleaved composite materials have exhibited improved damage tolerance and higher compression after impact behaviour compared to composites, which are noninterleaved. Interleaving layers embedded between plies are constrained and suppress the initiation of impact damage. This technique of interleaving enhances growth of crack-tip yield zone in the region between the plies [145]. Frequently used interleaving materials include thin thermoplastic films such as PEEA/PA film [146, 147], bisphenol A based epoxy [145], FM 300 epoxy resin [148,
149], PEI films [149], poly(ethylene-co-acrylic acid) PEAA $[150,151]$, polyethylene based films [152], epoxy modified with carboxyl-terminated butadiene acrylonitrile (CTBN) and polyurethane (PU) [153], cyanate ester/epoxy resin film [154], glass/epoxy softening strips [155], and nitride rubber modified epoxy interleaves [156]. However, degradation of hot/wet properties and inferior handling characteristics such as drape and tack have restricted the usage of this technology [157]. The major disadvantage of this technique is the weight penalty. The tough interlayers of resin have low stiffness and strength which proportionately reduce the in-plane stiffness and strength, requiring additional plies to maintain design properties [120].

5.5. Short Fibre Reinforcement (SFR). Research efforts have also been directed towards short fibre reinforcement in order to improve the impact resistance. There are two methods of fibre reinforcement in composite laminates; they are short fibre reinforcement (SFR) and translaminar reinforcement (TLR). TLR is discussed in the next subsection. In SFR, short fibres are deposited parallel to ply surface in the interlaminar region. SFR is often regarded as another method of interleaving due to the use of short fibres between the plies similar to the interleaving process. The distinction between SFR and interleaving however occurs on two levels. Addition of short fibres is distinctly different from addition of an interleaving film in that short fibres produce a randomly oriented heterogeneous layer. This creates potential for a random and disturbed crack path while the interleaving film creates additional two continuous interfacial zones.

Secondly, this technique of short fibre reinforcement induces semielastic failure mechanisms of fibre pull-out and fibre bridging effect, thus increasing the energy consumption for a given damage area during failure. The fibre bridging effect was highly enhanced by the number of short fibre ends and the interfacial bond strength between short fibres and the matrix material. Hence, short fibre methods rely on increasing the energy consumption for a given damage area using the semielastic failure mechanisms of pull-out or fibre breakage by fibre bridging effect $[147,158]$. Therefore, less overall laminate damage occurs due to the increased fracture toughness of SFR modified laminates. The interleaving film however 


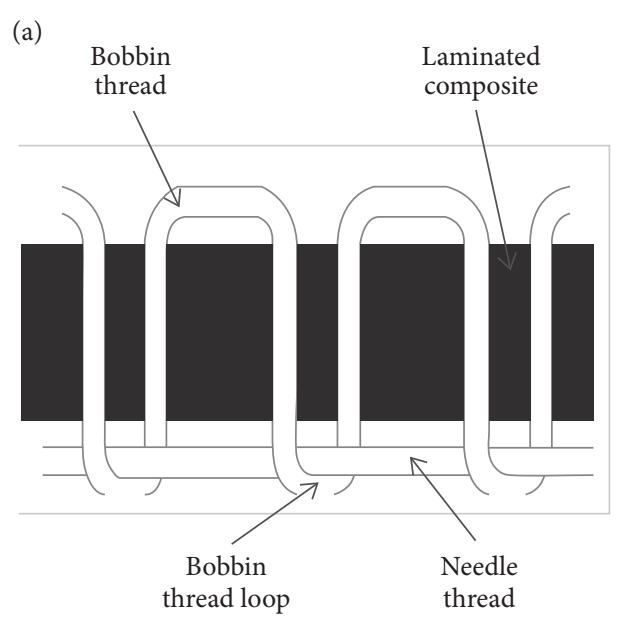

(a)

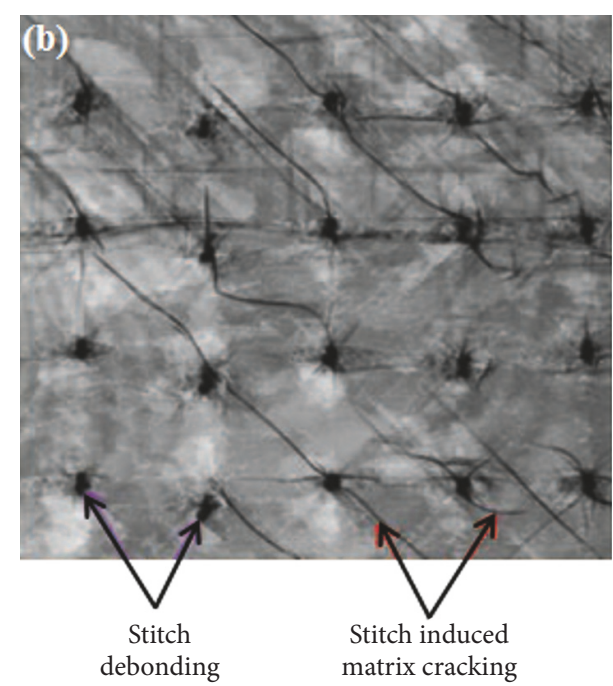

(b)

Figure 3: (a) Modified lock stitch. (b) Matrix cracking in stitched laminates [5].

absorbs energy by the mechanism of plastic deformation of the interlayer. This absorption of energy is regardless of the damage to the continuous fibres and matrix material. The use of short fibres as interlaminar reinforcement materials does not rely on the generation of plastic deformation for energy consumption. Materials used for short fibre reinforcements are Kevlar [146, 147, 159, 160] and Zylon fibres [146, 147]. Orientation of short fibres is a very important factor in the short fibre reinforcement method, which affects the mechanism of fracture as well as the mechanical properties. Difficulty in achieving random orientation of short fibres poses a major obstacle in this method.

5.6. Translaminar Reinforcement (TLR). In translaminar reinforcement, the fibrous reinforcement is across lamina interfaces in a translaminar fashion. Only a small amount of out-of-plane reinforcement (volume fractions less than 5\%) is required to significantly change the mechanical response of the laminate. Established and developed process such as stitching and Z-pinning offer effective means of achieving TLR or through-thickness reinforcement. Some of the other techniques for through-thickness reinforcement are 3D weaving, 3D braiding, 3D knitting, embroidery, tufting, and Z-anchoring $[158,161]$.

5.6.1. Stitching. This technique is a form of fibre reinforcement in the thickness direction making the laminate a $3 \mathrm{D}$ structure. A stitch needle carrying a high strength thread is inserted through the ply layers in this process. Influence of stitching on impact performance of composite laminates has been carefully studied for a number of composite material systems and the effect of stitching is found to be similar in many of these materials $[72,74,162-166]$. The extent to which stitching enhances damage resistance of composites has a crucial dependence on the impact velocity. Normally, stitching does not show improvement on impact resistance at low velocities, likely due to the short length of the delamination cracks. As the impact velocity increases, the effectiveness of stitching to enhance damage resistance seems to increase. The damage limiting ability of stitching then becomes higher with higher impact energy. Long delaminations are seen at relatively high energies, which enable complete development of a stitch bridging zone. This technique showed considerable improvement in its effectiveness with increasing stitching density $[167,168]$.

A study of impact damage mechanisms in a modified lock stitched laminates (Figure 3(a)) revealed that there is extensive matrix cracking induced by stitching [5]. The resin rich zones around stitch loops promote matrix crack initiation and these induced matrix cracks are diagonally connected by adjacent stitch loops (Figure 3(b)). Moreover, effects of $\mathrm{Z}$ direction fibre reinforcement of the composite laminates on their mechanical performance is a trade-off between interlaminar properties and their in-plane properties similar to others through the thickness reinforcing techniques [169, $170]$. Reduction of compression strength with the improvement of CAI strength is reported by Farley et al. [170].

5.6.2. Z-Pinning. Z-pinning is also involved through the thickness reinforcement of the prepreg laminates by the use of Z-pins which can be done commercially in large scale. Zpins act as fine nails that lock the laminate plies together by a combination of friction and adhesion. The term pin is used generically to describe all types of pin materials (i.e., metals pins, fibrous pins, etc.). Pins may be used for the wide area reinforcement of damage tolerant panels or used in selective areas requiring local reinforcement such as structural bonds, stiffener attachment, stress concentration, and holes. Z-pins fasten the plies of the laminate together by the mechanisms of adhesion and friction (refer to Figure 4). This technique can be implemented as selective region reinforcement or wide area reinforcement of composite panels. Delamination 


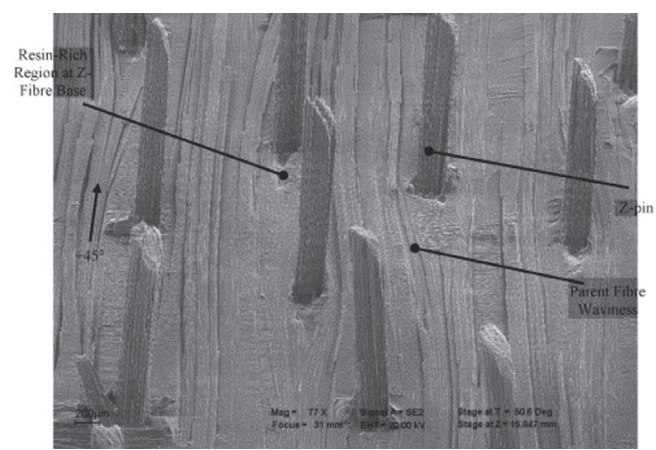

FIGURE 4: Z-pins reinforcements observed after pull-out [6].

resistance and damage tolerance of laminates during impact have been effectively improved by this technique $[161,168]$.

$\mathrm{Z}$-pinning has been shown to be beneficial in reducing impact damage both at low velocity impact and at high velocity impact such as ballistic projectiles [161, 171-175]. Zpins generate bridge traction forces which reduce impact damage and impede formation of very short delaminations. This technique also resulted in better residual properties after impact and higher buckling resistance of the damaged plies. Though this method produces improved impact damage tolerance, there is a pernicious influence on other mechanical properties such as strength, elastic modulus, and fatigue life of the composite laminates [173, 176-178]. Drawbacks associated with the TLR techniques (Z-pinning and stitching) are manufacturing and tooling costs. Established methods of TLR are both labour intensive and costly and require specialized equipment. Similarly, methods involved in stitching are complicated and labour intensive for vast majority of composite manufacturers. These disadvantages drive the search for simpler methods that provide ability of manufacturing for small and medium scale manufacturers of composite materials [147, 158].

5.7. Surface Modification of Fibres. Performance of fibre reinforced composites will be effective only when stress can transfer efficiently across the interface between the fibres and matrix. Fibre/matrix interface bond strength is one of the main factors influencing impact resistance and mechanical properties of composites. Polymer coatings along the fibre length, either fully or intermittently, have been explored. Fibre coatings may improve or degrade the fibre/matrix adhesion. In general, laminates having weak fibre/matrix adhesion show degraded impact performance due to debonding and extensive delamination. The residual flexural and CAI strength of such laminates with optimized fibre/matrix adhesion (fibre treatment) is typically superior to the laminates with poor adhesion. It is attributed to the higher delamination resistance of composite materials having fibres with surface modification [179].

Treatments on glass fibres that were investigated for the improvement of impact damage tolerance are silane coupling agent (epoxy dispersion on the base of bisphenol $\mathrm{A}$ with a $\gamma$-aminopropyltriethoxy) [179-181], silane coupling agents, $\gamma$-MPS and $\gamma$-GPS [182], coupling agent (Z-6020), and a compound for mold release [183] and spraying of emulsified polymer [184]. The influence of PVAL (polyvinyl alcohol) coating of carbon fibre on the impact performance has been investigated by Kim and Mai [185]. CNBN rubber and PVA coatings were also studied for Kevlar fibres [185].

5.8. Particle Based Interlayer Toughening. This technique involves formation of heterogeneous interlayers in composite laminates by effectively utilising preformed particles as a second phase, usually a thermoplastic or rubber [186]. Particle interlayer based modification of laminated composites is the best practical technique prevalent and it is an inexpensive and simple technique for improving impact performance of these composites [157]. There are three methods of incorporating particles into the polymer based composites: sprayup, double pass method, and single pass method. In sprayup and double pass method, particles are incorporated in interlayers of the prepreg laminates. First a prepreg intraply region is impregnated by a homogeneous resin without any toughening particles. Then another resin modified with particles is selectively coated on prepreg interlaminar region in double pass method and only the particles are sprayed up on the prepreg surface in spray-up method, whereas in the general or single pass impregnation method, first the particles are distributed in the matrix resin and then the modified resin is used in the prepreg manufacturing process. The particles will move out to the surface of the prepreg during the filming process.

This single pass method has disadvantages such as nonuniform particle distribution and degraded transverse integrity between adjacent fibre tows $[186,187]$. The former two methods (spray-up and double pass) are better than later method (single pass) in terms of processability and formation of multilayer structure in the case of former two methods. Influence of such particle based impregnation on interlaminar properties depends on the adhesion of particles to matrix resin and particle rigidity $[186,188]$.

5.8.1. Rubber Particles. Rubber based preformed particles have been explored for particle based interlayer modification of polymer composite materials. Many of these rubber based particles consist of functional group which can coreact with the polymer matrix of the composite. The rubber particles which have been used are CTBN (carboxyl-terminated butadiene acrylonitrile) based functionalised elastomers [186, 189] and other elastomeric particles [190]. Along with increasing impact toughness up to a certain concentration, rubber particles were found to increase tack of prepreg systems [190]. However, detrimental effects of rubber particles are reduced stiffness, glass transition temperature, mechanical strength, poor thermal stability, and additional complexity in composite processability along with lower hot-wet properties of composite materials [157, 187].

Due to the presence of soft phase in the thermosetting polymer matrix and deterioration of other mechanical properties, the utilisation of preformed rubber particles does not promise significant overall improvement. Hence, particles based on thermoplastic polymers are employed for increasing impact performance of polymer matrices. Thermoplastic 
particles based interlayer showed better overall mechanical properties, although it is not superior to elastomer particles in terms of toughness improvement [191, 192].

5.8.2. Thermoplastic Particles. In this approach, enhancement of impact fracture toughness is achieved by utilising superior fracture properties of thermoplastic resin and its good processability without sacrificing hot-wet properties [193]. Thermoplastic polymer particles are spread on the surface of the prepreg leading to modification of ply interfaces [148]. During creation of damage under impact loading, delaminations propagate in interlaminar regions; thereby extent of damage growth can be impeded by introducing thermoplastic based interlayer due to its superior toughness [148]. Polymer particles which are considered for improvement of impact properties are rigid amorphous polyamide particles [194, 195], nylon particles [160, 196-198], polyethersulfones [199], and unspecified thermoplastic particles [200, 201]. A new type of thermoplastic microparticles called core shell microparticles is dispersed in the interlaminar interfaces during fabrication to improve the damage resistance of the composite laminates [202-204]. The composite laminates showed overall reduced impact damage and higher peak load bearing capability but showed deterioration in in-plane flexural properties [203, 204].

\section{Conclusion}

It is obvious that susceptibility to damage due to low velocity impact is one of the predominant limitations in the usage of composite laminates. Advanced laminated structures are expected to perform their intended functions in an environment where low energy impact damage can occur from variety of sources such as tool dropping, hail stones, collisions, debris, or foreign object impact. Internal damage which is undetectable by naked eye but further propagates under typical loaded conditions is generated due to such low energy impacts. Residual mechanical performance of such structures deteriorates drastically in varying degrees in compression, tension, flexure, and fatigue. Various techniques of improving composite structures to mitigate impact damage have been studied by many researchers. Critical analysis and assessment of these techniques confirm that there have been several constraints in their implementation such as high tooling cost, design complexities, and subsequent problems in manufacturing and degradation in mechanical properties. Application of some of the above discussed techniques like interleaving, stitching, and particle based interlayer toughening leads to a trade-off between reduction of in-plane mechanical properties and improvement in transverse impact characteristics $[120,157,169,170,187,203,204]$. Thus, it necessitates further research towards achievement of superior impact performance without compromising the residual mechanical properties. Latest research in self-healing polymer composites inspired from biological systems promises new materials in future, which can activate autonomous healing of cracks immediately after crack initiation. New research in damage detection methods and sensing is expected to complement the self-healing composites in future.

\section{Conflicts of Interest}

The authors declare that there are no conflicts of interest regarding the publication of this paper.

\section{References}

[1] S. Mazumdar, Composites Manufacturing: Materials, Product, and Process Engineering, CRC Press, Boca Raton, Fla, USA, 2001.

[2] P. D. Mangalgiri, "Composite materials for aerospace applications," Bulletin of Materials Science, vol. 22, no. 3, pp. 657-664, 1999.

[3] S. Petit, C. Bouvet, A. Bergerot, and J.-J. Barrau, "Impact and compression after impact experimental study of a composite laminate with a cork thermal shield," Composites Science and Technology, vol. 67, no. 15-16, pp. 3286-3299, 2007.

[4] F. H. Gojny, M. H. G. Wichmann, B. Fiedler, W. Bauhofer, and K. Schulte, "Influence of nano-modification on the mechanical and electrical properties of conventional fibre-reinforced composites," Composites-Part A: Applied Science and Manufacturing, vol. 36, no. 11, pp. 1525-1535, 2005.

[5] K. T. Tan, N. Watanabe, and Y. Iwahori, "Impact damage resistance, response, and mechanisms of laminated composites reinforced by through-thickness stitching," International Journal of Damage Mechanics, vol. 21, no. 1, pp. 51-80, 2012.

[6] E. Greenhalgh, A. Lewis, R. Bowen, and M. Grassi, "Evaluation of toughening concepts at structural features in CFRP-Part I: Stiffener pull-off," Composites Part A: Applied Science and Manufacturing, vol. 37, no. 10, pp. 1521-1535, 2006.

[7] G. H. Staab, Laminar Composites, Butterworth-Heinemann, 1999.

[8] M. O. W. Richardson and M. J. Wisheart, "Review of lowvelocity impact properties of composite materials," Composites A, vol. 27, no. 12, pp. 1123-1131, 1996.

[9] C. A. Mahieux, Environmental Degradation in Industrial Composites, Elsevier, Oxford, UK, 2006.

[10] D. A. Bhagwan, J. B. Lawrence, and K. Chandrashekhara, Analysis and Performance of Fiber Composites, John Wiley \& Sons, Inc, Hoboken, NJ, USA, 2006.

[11] S. Abrate, Impact on Composite Structures, Cambridge University Press, Cambridge, UK, 1998.

[12] S. Georgiadis, A. J. Gunnion, R. S. Thomson, and B. K. Cartwright, "Bird-strike simulation for certification of the Boeing 787 composite moveable trailing edge," Composite Structures, vol. 86, no. 1-3, pp. 258-268, 2008.

[13] S. T. Jenq, F. B. Hsiao, I. C. Lin, D. G. Zimcik, and M. N. Ensan, "Simulation of a rigid plate hit by a cylindrical hemi-spherical tip-ended soft impactor," Computational Materials Science, vol. 39, no. 3, pp. 518-526, 2007.

[14] H. V. D. Zanden, “Composites' famously low impact tolerance," 2009, http://www.lonelyscientist.com/?p=486.

[15] D. Varas, R. Zaera, and J. López-Puente, "Experimental study of CFRP fluid-filled tubes subjected to high-velocity impact," Composite Structures, vol. 93, no. 10, pp. 2598-2609, 2011.

[16] P. Kumar and B. Rai, "Delaminations of barely visible impact damage in CFRP laminates," Composite Structures, vol. 23, no. 4, pp. 313-318, 1993.

[17] P. W. Manders and W. C. Harris, "Parametric study of composite performance in compression-after-impact testing," SAMPE Journal, vol. 22, no. 6, pp. 47-51, 1986. 
[18] A. Rotem, "Residual flexural strength of frp composite specimens subjected to transverse impact loading," SAMPE Journal, vol. 24, no. 2, pp. 19-25, 1988.

[19] W. J. Cantwell and J. Morton, "The impact resistance of composite materials-a review," Composites, vol. 22, no. 5, pp. 347362, 1991.

[20] S. Agrawal, K. K. Singh, and P. K. Sarkar, "Impact damage on fibre-reinforced polymer matrix composite - A review," Journal of Composite Materials, vol. 48, no. 3, pp. 317-332, 2014.

[21] D. Hull, "A unified approach to progressive crushing of fibrereinforced composite tubes," Composites Science and Technology, vol. 40, no. 4, pp. 377-421, 1991.

[22] G. L. Farley and R. M. Jones, "Crushing characteristics of continuous fiber-reinforced composite tubes," Journal of Composite Materials, vol. 26, no. 1, pp. 37-50, 1992.

[23] A. Fairfull and D. Hull, "Energy absorption of polymer matrix composite structures: frictional effects," in Structural Failure, T. Wierzbicki and D. Jones, Eds., pp. 255-279, John Wiley and Sons, New York, NY, USA, 1989.

[24] A. G. Mamalis, D. E. Manolakos, G. A. Demosthenous, and M. B. Ioannidis, "The static and dynamic axial collapse of fibreglass composite automotive frame rails," Composite Structures, vol. 34, no. 1, pp. 77-90, 1996.

[25] T. K. O'Brien, "Delamination of composite materials," in Fatigue of Composite Materials, K. L. Reifsnider, Ed., vol. 4 of Composite Materials Series, pp. 181-198, Elsevier, New York, NY, USA, 1991.

[26] N. J. Pagano and G. A. Schoeppner, "Delamination of polymer matrix composites: Problems and assessment," in in Comprehensive Composite Materials, A. Kelly and C. Zweben, Eds., pp. 433-528, Elsevier, London, UK, 2000.

[27] P. O. Sjoblom, J. T. Hartness, and T. M. Cordell, “On low-velocity impact testing of composite materials," Journal of Composite Materials, vol. 22, no. 1, pp. 30-52, 1988.

[28] K. N. Shivakumar, W. Elber, and W. Illg, "Prediction of lowvelocity impact damage in thin circular laminates," AIAA Journal, vol. 23, no. 3, pp. 442-449, 1985.

[29] P. Robinson and G. A. O. Davies, "Impactor mass and specimen geometry effects in low velocity impact of laminated composites," International Journal of Impact Engineering, vol. 12, no. 2, pp. 189-207, 1992.

[30] D. A. O. Davies and P. Robinson, "Predicting failure by debonding/delamination," in Proceedings of the AGARD: 74th Structures and Materials Meeting, Patras, Greece.

[31] D. Liu and L. E. Malvern, "Matrix cracking in impacted glass/epoxy plates," Journal of Composite Materials, vol. 21, no. 7, pp. 594-609, 1987.

[32] S. P. Joshi and C. T. Sun, "Impact-induced fracture initiation and detailed dynamic stress field in the vicinity of impact," in Proceedings of the 2 nd technical Conference on American Society of Composites, Newark, NJ, USA, 1987.

[33] S. Abrate, "Modeling of impacts on composite structures," Composite Structures, vol. 51, no. 2, pp. 129-138, 2001.

[34] N. K. Naik, Y. Chandra Sekher, and S. Meduri, "Damage in woven-fabric composites subjected to low-velocity impact," Composites Science and Technology, vol. 60, no. 5, pp. 731-744, 2000.

[35] A. F. Johnson, A. K. Pickett, and P. Rozycki, "Computational methods for predicting impact damage in composite structures," Composites Science and Technology, vol. 61, no. 15, pp. 2183-2192, 2001.
[36] L. Iannucci and M. L. Willows, "An energy based damage mechanics approach to modelling impact onto woven composite materials-Part I: Numerical models," Composites Part A: Applied Science and Manufacturing, vol. 37, no. 11, pp. 20412056, 2006.

[37] G. Reyes and U. Sharma, "Modeling and damage repair of woven thermoplastic composites subjected to low velocity impact," Composite Structures, vol. 92, no. 2, pp. 523-531, 2010.

[38] I. M. Daniel, E. E. Gdoutos, K.-A. Wang, and J. L. Abot, "Failure modes of composite sandwich beams," International Journal of Damage Mechanics, vol. 11, no. 4, pp. 309-334, 2002.

[39] M. Zako and Y. Uetsuji, "On the damage behavior of fiber reinforced composite materials," International Journal of Damage Mechanics, vol. 11, no. 2, pp. 187-202, 2002.

[40] T. E. Tay, G. Liu, A. Yudhanto, and V. B. C. Tan, "A micromacro approach to modeling progressive damage in composite structures," International Journal of Damage Mechanics, vol. 17, no. 1, pp. 5-28, 2008.

[41] A. Louhghalam and S. R. Arwade, "Prediction of incipient damage sites in composites using classifiers," International Journal of Damage Mechanics, vol. 19, no. 2, pp. 233-260, 2010.

[42] Y. Tang, B. Sun, and B. Gu, "Impact damage of 3D cellular woven composite from unit-cell level analysis," International Journal of Damage Mechanics, vol. 20, no. 3, pp. 323-346, 2011.

[43] A. J. Lesser and A. G. Filippov, "Mechanisms governing the damage resistance of laminated composites subjected to lowvelocity impacts," International Journal of Damage Mechanics, vol. 3, no. 4, pp. 408-432, 1994.

[44] D. C. lo and D. H. Allen, "Modeling of Delamination Damage Evolution in Laminated Composites Subjected to Low Velocity Impact," International Journal of Damage Mechanics, vol. 3, no. 4, pp. 378-407, 1994.

[45] S. Abrate, "Impact on laminated composite materials," Applied Mechanics Reviews, vol. 44, no. 4, pp. 155-190, 1991.

[46] S. Abrate, "Impact on laminated composites: recent advances," Applied Mechanics Reviews, vol. 47, no. 11, pp. 517-544, 1994.

[47] W. Wang, X. Wan, J. Zhou et al., "Damage and failure of laminated carbon-fiber-reinforced composite under low-velocity impact," Journal of Aerospace Engineering, vol. 27, no. 2, pp. 308317, 2014.

[48] J. P. Hou and G. Jeronimidis, "Bending stiffness of composite plates with delamination," Composites Part A: Applied Science and Manufacturing, vol. 31, no. 2, pp. 121-132, 2000.

[49] J. P. Hou, N. Petrinic, and C. Ruiz, "A delamination criterion for laminated composites under low-velocity impact," Composites Science and Technology, vol. 61, no. 14, pp. 2069-2074, 2001.

[50] C. F. Li, N. Hu, J. G. Cheng, H. Fukunaga, and H. Sekine, "Lowvelocity impact-induced damage of continuous fiber-reinforced composite laminates. Part II. Verification and numerical investigation," Composites Part A: Applied Science and Manufacturing, vol. 33, no. 8, pp. 1063-1072, 2002.

[51] C. F. Li, N. Hu, Y. J. Yin, H. Sekine, and H. Fukunaga, "Low-velocity impact-induced damage of continuous fiberreinforced composite laminates. Part I. An FEM numerical model," Composites Part A: Applied Science and Manufacturing, vol. 33, no. 8, pp. 1055-1062, 2002.

[52] Y. Xu, W. Wen, and H. Cui, "A cumulative damage prediction method of low-velocity impacts on laminated composites," Materials Science and Engineering-Hangzhou, vol. 24, no. 1, pp. 77-82, 2006. 
[53] Y. Xu, W. Wen, and H. Cui, "Prediction method for fatigue life of laminated composites after impact under compressioncompression loading," Acta Materiae Compositae Sinica, vol. 24, no. 2, pp. 159-167, 2007.

[54] W. J. Cantwell, "The influence of target geometry on the high velocity impact response of CFRP," Composite Structures, vol. 10, no. 3, pp. 247-265, 1988.

[55] W. J. Cantwell and J. Morton, "Comparison of the low and high velocity impact response of cfrp," Composites, vol. 20, no. 6, pp. 545-551, 1989.

[56] L. H. Strait, M. L. Karasek, and M. F. Amateau, "Effects of stacking sequence on the impact resistance of carbon fiber reinforced thermoplastic toughened epoxy laminates," Journal of Composite Materials, vol. 26, no. 12, pp. 1725-1740, 1992.

[57] E. Fuoss, P. V. Straznicky, and C. Poon, "Effects of stacking sequence on the impact resistance in composite laminates - Part 1: Parametric study," Composite Structures, vol. 41, no. 1, pp. 6777, 1998.

[58] E. Fuoss, P. V. Straznicky, and C. Poon, "Effects of stacking sequence on the impact resistance in composite laminates. Part 2: Prediction method," Composite Structures, vol. 41, no. 2, pp. 177-186, 1998.

[59] L. S. Sutherland and C. Guedes Soares, "Impact behaviour of typical marine composite laminates," Composites Part B: Engineering, vol. 37, no. 2-3, pp. 89-100, 2005.

[60] E. G. Guynn and T. K. O’Brien, "Influence of lay-up and thickness on composite impact damage and compression strength," in Proceedings of the Collection of Technical Papers AIAA/ASME/ASCE/AHS 26th Structures, Structural Dynamics and Materials Conference., pp. 187-196.

[61] J. Morton, "Scaling of impact-loaded carbon-fiber composites," AIAA Journal, vol. 26, no. 8, pp. 989-994, 1988.

[62] B. V. Sankar, "Scaling of low-velocity impact for symmetric composite laminates," Journal of Reinforced Plastics and Composites, vol. 11, no. 3, pp. 296-309, 1992.

[63] D. Liu, B. B. Raju, and X. Dang, "Size effects on impact response of composite laminates," International Journal of Impact Engineering, vol. 21, no. 10, pp. 837-854, 1998.

[64] D. K. Maiti and P. K. Sinha, "Bending, free vibration and impact response of thick laminated composite plates," Computers and Structures, vol. 59, no. 1, pp. 115-129, 1996.

[65] Y. Qian, S. R. Swanson, R. J. Nuismer, and R. B. Bucinell, "An experimental study of scaling rules for impact damage in fiber composites," Journal of Composite Materials, vol. 24, no. 5, pp. 559-570, 1990.

[66] S. J. Kim and N. S. Goo, "Dynamic contact responses of laminated composite plates according to the impactor's shapes," Computers and Structures, vol. 65, no. 1, pp. 83-90, 1997.

[67] S.-M. Lee, J.-S. Cheon, and Y.-T. Im, "Experimental and numerical study of the impact behavior of SMC plates," Composite Structures, vol. 47, no. 1-4, pp. 551-561, 1999.

[68] R. A. W. Mines, A. M. Roach, and N. Jones, "High velocity perforation behaviour of polymer composite laminates," International Journal of Impact Engineering, vol. 22, no. 6, pp. 561$588,1999$.

[69] G. Zhou, J. C. Lloyd, and J. J. McGuirk, "Experimental evaluation of geometric factors affecting damage mechanisms in carbon/epoxy plates," Composites Part A: Applied Science and Manufacturing, vol. 32, no. 1, pp. 71-84, 2001.

[70] T. Mitrevski, I. H. Marshall, R. Thomson, R. Jones, and B. Whittingham, "The effect of impactor shape on the impact response of composite laminates," Composite Structures, vol. 67, no. 2, pp. 139-148, 2005.

[71] G. Zhou, "Damage mechanisms in composite laminates impacted by a flat-ended impactor," Composites Science and Technology, vol. 54, no. 3, pp. 267-273, 1995.

[72] M. B. Dow and D. L. Smith, "Damage-tolerant composite materials produced by stitching carbon fabrics," in Proceedings of the 21st International SAMPE Technical Conference, pp. 595605, September 1989.

[73] K. Dransfield, C. Baillie, and Y.-W. Mai, "Improving the delamination resistance of CFRP by stitching-a review," Composites Science and Technology, vol. 50, no. 3, pp. 305-317, 1994.

[74] S. K. Sharma and B. V. Sankar, "Effect of stitching on impact and interlaminar properties of graphite/epoxy laminates," Journal of Thermoplastic Composite Materials, vol. 10, no. 3, pp. 241-253, 1997.

[75] K. Berketis and D. Tzetzis, "The compression-after-impact strength of woven and non-crimp fabric reinforced composites subjected to long-term water immersion ageing," Journal of Materials Science, vol. 45, no. 20, pp. 5611-5623, 2010.

[76] K. Berketis, D. Tzetzis, and P. J. Hogg, “The influence of long term water immersion ageing on impact damage behaviour and residual compression strength of glass fibre reinforced polymer (GFRP)," Materials and Design, vol. 29, no. 7, pp. 1300-1310, 2008.

[77] K. Berketis and D. Tzetzis, "Long-term water immersion ageing characteristics of GFRP composites," Journal of Materials Science, vol. 44, no. 13, pp. 3578-3588, 2009.

[78] S. Zainuddin, M. V. Hosur, Y. Zhou, A. Kumar, and S. Jeelani, "Durability study of neat/nanophased GFRP composites subjected to different environmental conditioning," Materials Science and Engineering A, vol. 527, no. 13-14, pp. 3091-3099, 2010.

[79] A. Zafar, F. Bertocco, J. Schjødt-Thomsen, and J. C. Rauhe, "Investigation of the long term effects of moisture on carbon fibre and epoxy matrix composites," Composites Science and Technology, vol. 72, no. 6, pp. 656-666, 2012.

[80] M. K. Hossain, M. M. R. Chowdhury, K. A. Imran et al., "Effect of low velocity impact responses on durability of conventional and nanophased CFRP composites exposed to seawater," Polymer Degradation and Stability, vol. 99, no. 1, pp. 180-189, 2014.

[81] C. L. Schutte, "Environmental durability of glass-fiber composites," Materials Science and Engineering R, vol. 13, no. 7, pp. 265323, 1994.

[82] A. D. Kelkar, J. Sankar, and K. Rajeev, "Analysis of tensile preloaded composites subjected to low-velocity impact loads," in Proceedings of the 39th AIAA/ASME/ASCE/AHS/ASC Structures, Structural Dynamics, and Materials Conference and Exhibit and AIAA/ASME/AHS Adaptive Structures Forum, pp. 1978-1987, Long Beach, Calif, USA, April 1998.

[83] T. Mitrevski, I. H. Marshall, R. S. Thomson, and R. Jones, "Lowvelocity impacts on preloaded GFRP specimens with various impactor shapes," Composite Structures, vol. 76, no. 3, pp. 209$217,2006$.

[84] B. Whittingham, I. H. Marshall, T. Mitrevski, and R. Jones, “The response of composite structures with pre-stress subject to low velocity impact damage," Composite Structures, vol. 66, no. 1-4, pp. 685-698, 2004.

[85] M. D. Robb, W. S. Arnold, and I. H. Marshall, "The damage tolerance of GRP laminates under biaxial prestress," Composite Structures, vol. 32, no. 1-4, pp. 141-149, 1995. 
[86] J. W. Gillespie Jr., "Damage tolerance of composite structures. The role of interlaminar fracture mechanics," Journal of Offshore Mechanics and Arctic Engineering, vol. 113, no. 3, pp. 247-252, 1991.

[87] S.-X. Wang, L.-Z. Wu, and L. Ma, "Low-velocity impact and residual tensile strength analysis to carbon fiber composite laminates," Materials and Design, vol. 31, no. 1, pp. 118-125, 2010.

[88] M. S. El-Zein and K. L. Reifsnider, "On the prediction of tensile strength after impact of composite laminates," Journal of Composites Technology and Research, vol. 12, no. 3, pp. 147-154, 1990.

[89] J.-M. Koo, J.-H. Choi, and C.-S. Seok, "Evaluation for residual strength and fatigue characteristics after impact in CFRP composites," Composite Structures, vol. 105, pp. 58-65, 2013.

[90] D. D. R. Cartié and P. E. Irving, "Effect of resin and fibre properties on impact and compression after impact performance of CFRP," Composites - Part A: Applied Science and Manufacturing, vol. 33, no. 4, pp. 483-493, 2002.

[91] E. F. Dost, L. B. Ilcewiz, W. B. Avery, and B. R. Coxon, "Effects of stacking sequence on impact damage resistance and residual strength for quasi-isotropic laminates," in Composites Materials: Fatigue And Fracture, ASTM STP 1110, T. K. O'Brien, Ed., pp. 476-500, American Society for Testing and Materials, Philadelphia, Pa, USA.

[92] S. Sanchez-Saez, E. Barbero, R. Zaera, and C. Navarro, "Compression after impact of thin composite laminates," Composites Science and Technology, vol. 65, no. 13, pp. 1911-1919, 2005.

[93] A. Duarte, I. Herszberg, and R. Paton, "Impact resistance and tolerance of interleaved tape laminates," Composite Structures, vol. 47, no. 1-4, pp. 753-758, 1999.

[94] Z. Y. Zhang and M. O. W. Richardson, "Low velocity impact induced damage evaluation and its effect on the residual flexural properties of pultruded GRP composites," Composite Structures, vol. 81, no. 2, pp. 195-201, 2007.

[95] C. He, Y. Li, Z. Zhang, and Z. Sun, "Impact damage modes and residual flexural properties of composites beam," Journal of Reinforced Plastics and Composites, vol. 27, no. 11, pp. 1163-1175, 2008.

[96] A. P. Mouritz, J. Gallagher, and A. A. Goodwin, "Flexural strength and interlaminar shear strength of stitched GRP laminates following repeated impacts," Composites Science and Technology, vol. 57, no. 5, pp. 509-522, 1997.

[97] R. L. Ramkumar, "Effect of low-velocity impact damage on the fatigue behavior of graphite/epoxy laminates," in ASTM STP 813, T. K. O’Brien, Ed., pp. 116-135, American Society for Testing and Materials, Philadelphia, Pa, USA, 1983.

[98] N. H. Tai, C. C. M. Ma, J. M. Lin, and G. Y. Wu, "Effects of thickness on the fatigue-behavior of quasi-isotropic carbon/epoxy composites before and after low energy impacts," Composites Science and Technology, vol. 59, no. 11, pp. 1753-1762, 1999.

[99] L. G. Melin, J. Schön, and T. Nyman, "Fatigue testing and buckling characteristics of impacted composite specimens," International Journal of Fatigue, vol. 24, no. 2-4, pp. 263-272, 2002.

[100] D. D. Symons and G. Davis, "Fatigue testing of impact-damaged T300/914 carbon-fibre-reinforced plastic," Composites Science and Technology, vol. 60, no. 3, pp. 379-389, 2000.

[101] M. S. Rosenfeld and L. W. Gause, "Compression fatigue behaviour of graphite/epoxy in the presence of stress raisers," in Fatigue of Fibrous Composite Materials in ASTM STP 723, pp. 174-196, American Society for Testing and Materials, 1981.
[102] S. R. Swanson, D. S. Cairns, M. E. Guyll, and D. Johnson, "Compression fatigue response for carbon fiber with conventional and toughened epoxy matrices with damage," Journal of Engineering Materials and Technology, Transactions of the ASME, vol. 115, no. 1, pp. 116-121, 1993.

[103] G. Clark and T. J. Van Blaricum, "Load spectrum modification effects on fatigue of impact-damaged carbon fibre composite coupons," Composites, vol. 18, no. 3, pp. 243-251, 1987.

[104] D. F. Adams and A. K. Miller, "An analysis of the impact behavior of hybrid composite materials," Materials Science and Engineering, vol. 19, no. 2, pp. 245-260, 1975.

[105] M. T. Dehkordi, H. Nosraty, M. M. Shokrieh, G. Minak, and D. Ghelli, "Low velocity impact properties of intra-ply hybrid composites based on basalt and nylon woven fabrics," Materials and Design, vol. 31, no. 8, pp. 3835-3844, 2010.

[106] N. K. Naik, V. Ch, and V. R. Kavala, "Hybrid composites under high strain rate compressive loading," Materials Science and Engineering A, vol. 498, no. 1-2, pp. 87-99, 2008.

[107] Y.-S. Lee, K.-H. Kang, and O. Park, "Response of hybrid laminated composite plates under low-velocity impact," Computers and Structures, vol. 65, no. 6, pp. 965-974, 1997.

[108] K. S. Pandya, C. Veerraju, and N. K. Naik, "Hybrid composites made of carbon and glass woven fabrics under quasi-static loading," Materials and Design, vol. 32, no. 7, pp. 4094-4099, 2011.

[109] G. Dorey, G. R. Sidey, and J. Hutchings, "Impact properties of carbon fibre/Kevlar 49 fibre hydrid composites," Composites, vol. 9, no. 1, pp. 25-32, 1978.

[110] M. V. Hosur, M. Adbullah, and S. Jeelani, "Studies on the low-velocity impact response of woven hybrid composites," Composite Structures, vol. 67, no. 3, pp. 253-262, 2005.

[111] D. W. Woods, P. J. Hine, and I. M. Ward, "The impact properties of hybrid composites reinforced with high-modulus polyethylene fibres and glass fibres," Composites Science and Technology, vol. 52, no. 3, pp. 397-405, 1994.

[112] N. K. Naik, R. Ramasimha, H. Arya, S. V. Prabhu, and N. ShamaRao, "Impact response and damage tolerance characteristics of glass-carbon/epoxy hybrid composite plates," Composites Part B:Engineering, vol. 32, no. 7, pp. 565-574, 2001.

[113] E. Sevkat, B. Liaw, F. Delale, and B. B. Raju, "Drop-weight impact of plain-woven hybrid glass-graphite/toughened epoxy composites," Composites Part A: Applied Science and Manufacturing, vol. 40, no. 8, pp. 1090-1110, 2009.

[114] B. Harris and A. R. Bunsell, "Impact properties of glass fibre/carbon fibre hybrid composites," Composites, vol. 6, no. 5, pp. 197-201, 1975.

[115] A. Pegoretti, E. Fabbri, C. Migliaresi, and F. Pilati, "Intraply and interply hybrid composites based on E-glass and poly(vinyl alcohol) woven fabrics: Tensile and impact properties," Polymer International, vol. 53, no. 9, pp. 1290-1297, 2004.

[116] X. Wang, B. Hu, Y. Feng et al., "Low velocity impact properties of 3D woven basalt/aramid hybrid composites," Composites Science and Technology, vol. 68, no. 2, pp. 444-450, 2008.

[117] R. Park and J. Jang, "The effects of hybridization on the mechanical performance of aramid/polyethylene intraply fabric composites," Composites Science and Technology, vol. 58, no. 10, pp. 1621-1628, 1998.

[118] M. N. Ghasemi Nejhad and A. Parvizi-Majidi, "Impact behaviour and damage tolerance of woven carbon fibre-reinforced thermoplastic composites," Composites, vol. 21, no. 2, pp. 155$168,1990$. 
[119] D. C. Leach and D. R. Moore, "Toughness of aromatic polymer composites reinforced with carbon fibres," Composites Science and Technology, vol. 23, no. 2, pp. 131-161, 1985.

[120] N. Sela and O. Ishai, "Interlaminar fracture toughness and toughening of laminated composite materials: a review," Composites, vol. 20, no. 5, pp. 423-435, 1989.

[121] K. Kageyama, T. Kobayashi, N. Yanagisawa, M. Kikuchi, and H. Miyamoto, "Mode I interlaminar fracture mechanics of unidirectionally reinforced carbon/nylon laminates," Transactions of the Japan Society of Mechanical Engineers Series A, vol. 53, no. 496, pp. 2386-2393, 1987.

[122] K. Tohgo, Y. Hirako, H. Ishii, and K. Sano, "Mode I interlaminar fracture toughness and fracture mechanism of angle-ply carbon/nylon laminates," Journal of Composite Materials, vol. 30, no. 6, pp. 650-661, 1996.

[123] K.-Y. Kim, L. Ye, and K.-M. Phoa, "Interlaminar fracture toughness of CF/PEI and GF/PEI composites at elevated temperatures," Applied Composite Materials, vol. 11, no. 3, pp. 173190, 2004.

[124] N. H. Tai, C. C. M. Ma, and S. H. Wu, "Fatigue behaviour of carbon fibre/PEEK laminate composites," Composites, vol. 26, no. 8, pp. 551-559, 1995.

[125] C. Henaff-Gardin and M. C. Lafarie-Frenot, "Fatigue behaviour of thermoset and thermoplastic cross-ply laminates," Composites, vol. 23, no. 2, pp. 109-116, 1992.

[126] D. C. Curtis, D. R. Moore, B. Slater, and N. Zahlan, "Fatigue testing of multi-angle laminates of CF/PEEK," Composites, vol. 19, no. 6, pp. 446-452, 1988.

[127] M. Buggy and G. Dillon, "Flexural fatigue of carbon fibrereinforced PEEK laminates," Composites, vol. 22, no. 3, pp. 191198, 1991.

[128] J.-K. Kim, D. B. MacKay, and Y.-W. Mai, "Drop-weight impact damage tolerance of CFRP with rubber-modified epoxy matrix," Composites, vol. 24, no. 6, pp. 485-494, 1993.

[129] J. Kim, C. Baillie, J. Poh, and Y.-W. Mai, "Fracture toughness of CFRP with modified epoxy resin matrices," Composites Science and Technology, vol. 43, no. 3, pp. 283-297, 1992.

[130] G. Levita, L. Di Landro, and A. Marchetti, "Interface strength in composites having epoxy matrix toughened with reactive rubber," Plastics, Rubber and Composites Processing and Applications, vol. 26, no. 6, pp. 250-255, 1997.

[131] M. Higashino, K.-I. Takemura, and T. J. Fujii, "Strength and damage accumulation of carbon fabric composites with a crosslinked NBR modified epoxy under static and cyclic loadings," Composite Structures, vol. 32, no. 1-4, pp. 357-366, 1995.

[132] K. Takemura and T. Fujii, "Improvement in static, impact and fatigue properties of CFRP due to CNBR modification of epoxy matrix," JSME International Journal, Series A: Solid Mechanics and Material Engineering, vol. 43, no. 2, pp. 186-195, 2000.

[133] K. Takemura, "Fracture toughness of carbon fiber reinforced composites with rubber modification," Key Engineering Materials, vol. 334-335, pp. 509-512, 2007.

[134] A. C. Garg and Y.-W. Mai, "Failure prediction in toughened epoxy resins," Composites Science and Technology, vol. 31, no. 3, pp. 225-242, 1988.

[135] A. C. Garg and Y.-W. Mai, "Failure mechanisms in toughened epoxy resins-A review," Composites Science and Technology, vol. 31, no. 3, pp. 179-223, 1988.

[136] V. Kostopoulos, A. Baltopoulos, P. Karapappas, A. Vavouliotis, and A. Paipetis, "Impact and after-impact properties of carbon fibre reinforced composites enhanced with multi-wall carbon nanotubes," Composites Science and Technology, vol. 70, no. 4, pp. 553-563, 2010.

[137] M. Hussain, A. Nakahira, and K. Niihara, "Mechanical property improvement of carbon fiber reinforced epoxy composites by Al2O3 filler dispersion," Materials Letters, vol. 26, no. 3, pp. 185191, 1996.

[138] B. Wetzel, F. Haupert, K. Friedrich, M. Q. Zhang, and M. Z. Rong, "Impact and wear resistance of polymer nanocomposites at low filler content," Polymer Engineering and Science, vol. 42, no. 9, pp. 1919-1927, 2002.

[139] T. H. Hsieh, A. J. Kinloch, K. Masania, J. Sohn Lee, A. C. Taylor, and S. Sprenger, "The toughness of epoxy polymers and fibre composites modified with rubber microparticles and silica nanoparticles," Journal of Materials Science, vol. 45, no. 5, pp. 1193-1210, 2010.

[140] Y. Ye, H. Chen, J. Wu, and C. M. Chan, "Interlaminar properties of carbon fiber composites with halloysite nanotube-toughened epoxy matrix," Composites Science and Technology, vol. 71, no. 5, pp. 717-723, 2011.

[141] M. V. Hosur, F. Chowdhury, and S. Jeelani, "Low-velocity impact response and ultrasonic NDE of woven carbon/epoxy-nanoclay nanocomposites," Journal of Composite Materials, vol. 41, no. 18, pp. 2195-2212, 2007.

[142] K. Iqbal, S.-U. Khan, A. Munir, and J.-K. Kim, "Impact damage resistance of CFRP with nanoclay-filled epoxy matrix," Composites Science and Technology, vol. 69, no. 11-12, pp. 1949-1957, 2009.

[143] S. U. Khan, K. Iqbal, A. Munir, and J.-K. Kim, "Quasi-static and impact fracture behaviors of CFRPs with nanoclay-filled epoxy matrix," Composites Part A: Applied Science and Manufacturing, vol. 42, no. 3, pp. 253-264, 2011.

[144] M. H. G. Wichmann, J. Sumfleth, F. H. Gojny, M. Quaresimin, B. Fiedler, and K. Schulte, "Glass-fibre-reinforced composites with enhanced mechanical and electrical properties-benefits and limitations of a nanoparticle modified matrix," Engineering Fracture Mechanics, vol. 73, no. 16, pp. 2346-2359, 2006.

[145] S. N. Yadav, V. Kumar, and S. K. Verma, "Fracture toughness behaviour of carbon fibre epoxy composite with Kevlar reinforced interleave," Materials Science and Engineering B: SolidState Materials for Advanced Technology, vol. 132, no. 1-2, pp. 108-112, 2006.

[146] M. S. Sohn, X. Z. Hu, J. K. Kim, and L. Walker, "Impact damage characterization of carbon fibre/epoxy composites with multilayer reinforcement," Composites Part B: Engineering, vol. 31, no. 8, pp. 681-691, 2000.

[147] L. Walker, M.-S. Sohn, and X.-Z. Hu, "Improving impact resistance of carbon-fibre composites through interlaminar reinforcement," Composites - Part A: Applied Science and Manufacturing, vol. 33, no. 6, pp. 893-902, 2002.

[148] S. Ogihara, N. Takeda, and A. Kobayashi, "Experimental characterization of microscopic failure process under quasi-static tension in interleaved and toughness-improved CFRP cross-ply laminates," Composites Science and Technology, vol. 57, no. 3, pp. 267-275, 1997.

[149] R. F. Gibson, Y. Chen, and H. Zhao, "Improvement of vibration damping capacity and fracture toughness in composite laminates by the use of polymeric interleaves," Journal of Engineering Materials and Technology, Transactions of the ASME, vol. 123, no. 3, pp. 309-314, 2001.

[150] W. H. Lu, F. S. Liao, A. C. Su, P. W. Kao, and T. J. Hsu, "Effect of interleaving on the impact response of a unidirectional 
carbon/epoxy composite," Composites, vol. 26, no. 3, pp. 215222, 1995.

[151] W. H. Lu, P. W. Kao, and A. C. Su, "Flexural failure of unidirectional carbon/epoxy composites: Effects of interleaving and flexural rate," Journal of Polymer Research, vol. 5, no. 3, pp. 133$142,1998$.

[152] T. Tanimoto, "Suppression of interlaminar damage in carbon/epoxy laminates by use of interleaf layers," Scripta Metallurgica et Materiala, vol. 31, no. 8, pp. 1073-1078, 1994.

[153] S. F. Chen and B. Z. Jang, "Fracture behaviour of interleaved fiber-resin composites," Composites Science and Technology, vol. 41, no. 1, pp. 77-97, 1991.

[154] S. Singh and I. K. Partridge, "Mixed-mode fracture in an interleaved carbon-fibre/epoxy composite," Composites Science and Technology, vol. 55, no. 4, pp. 319-327, 1995.

[155] C. T. Sun and J. Luo, "Failure loads for notched graphite/epoxy laminates with a softening strip," Composites Science and Technology, vol. 22, no. 2, pp. 121-133, 1985.

[156] A. Aksoy and L. A. Carlsson, "Interlaminar shear fracture of interleaved graphite/epoxy composites," Composites Science and Technology, vol. 43, no. 1, pp. 55-69, 1992.

[157] E. N. Gilbert, B. S. Hayes, and J. C. Seferis, "Interlayer toughened unidirectional carbon prepreg systems: Effect of preformed particle morphology," Composites Part A: Applied Science and Manufacturing, vol. 34, no. 3, pp. 245-252, 2003.

[158] L. C. Dickinson, G. L. Farley, and M. K. Hinders, "Translaminar reinforced composites: a review," Journal of Composites Technology and Research, vol. 21, no. 1, pp. 3-15, 1999.

[159] M. S. Sohn and X. Z. Hu, "Impact and high strain rate delamination characteristics of carbon fibre epoxy composites," Theoretical and Applied Fracture Mechanics, vol. 25, no. 1, pp. 17-29, 1996.

[160] B. Y. Park, S. C. Kim, and B. Jung, "Interlaminar fracture toughness of carbon fiber/epoxy composites using short Kevlar fiber and/or Nylon-6 powder reinforcement," Polymers for Advanced Technologies, vol. 8, no. 6, pp. 371-377, 1997.

[161] A. P. Mouritz, "Review of z-pinned composite laminates," Composites Part A: Applied Science and Manufacturing, vol. 38, no. 12, pp. 2383-2397, 2007.

[162] G. A. Bibo and P. J. Hogg, "The role of reinforcement architecture on impact damage mechanisms and post-impact compression behaviour," Journal of Materials Science, vol. 31, no. 5, pp. 1115-1137, 1996.

[163] C. Caneva, S. Olivieri, C. Santulli, and G. Bonifazi, "Impact damage evaluation on advanced stitched composites by means of acoustic emission and image analysis," Composite Structures, vol. 25, no. 1-4, pp. 121-128, 1993.

[164] D. Liu, "Delamination in stitched and nonstitched composite plates subjected to low-velocity impact," in Proceedings of the American Society for Composites, Second Technical Conference, Newark, NJ, USA, 1987.

[165] E. Wu and J. Liau, "Impact of unstitched and stitched laminates by line loading," Journal of Composite Materials, vol. 28, no. 17, pp. 1640-1658, 1994.

[166] E. Wu and J. Wang, "Behavior of Stitched Laminates under In-Plane Tensile and Transverse Impact Loading," Journal of Composite Materials, vol. 29, no. 17, pp. 2254-2279, 1995.

[167] D. Liu, "Photoelastic study on composite stitching," Experimental Techniques, vol. 14, no. 1, pp. 25-27, 1990.

[168] L. Tong, A. P. Mouritz, and M. K. Bannister, 3D Fibre Reinforced Polymer Composites, Elsevier Science, Oxford, UK, 2002.
[169] A. P. Mouritz, K. H. Leong, and I. Herszberg, "A review of the effect of stitching on the in-plane mechanical properties of fibre-reinforced polymer composites," Composites Part A: Applied Science and Manufacturing, vol. 28, no. 12, pp. 979-991, 1997.

[170] G. L. Farley, B. T. Smith, and J. Maiden, "Compression response of thick layer composite laminates with through-the-thickness reinforcement," Journal of Reinforced Plastics and Composites, vol. 11, no. 7, pp. 787-810, 1992.

[171] G. Freitas, C. Magee, P. Dardzinski, and T. Fusco, "Fiber insertion process for improved damage tolerance in aircraft laminates," Journal of Advanced Materials, vol. 25, pp. 36-43, 1994.

[172] I. K. Partridge, D. D. R. Cartie, and T. Bonnington, "Manufacture and performance of Z-pinned composites," in Advanced Polymeric Composites: Structure Property Relationships, G. Shonaike and S. Advani, Eds., CRC Press LLC, 2003.

[173] I. K. Partridge, D. D. R. Cartie, M. Troulis, M. Grassi, and X. Zhang, "Evaluating the mechanical effectiveness of Z-pinning," in Proceedings of the in Proceedings of the SAMPE technical conference, 2004.

[174] A. Clarke, E. Greenhalgh, C. Meeks, and C. Jones, "Enhanced structural damage tolerance of CFRP primary structures by Z-pin reinforcement," in Proceedings of the 44th AIAA/ASME/ ASCE/AHS/ASC Structures, Structural Dynamics, and Materials Conference, April 2003.

[175] X. Zhang, L. Hounslow, and M. Grassi, "Improvement of lowvelocity impact and compression-after-impact performance by z-fibre pinning," Composites Science and Technology, vol. 66, no. 15, pp. 2785-2794, 2006.

[176] P. Chang, A. P. Mouritz, and B. N. Cox, "Flexural properties of z-pinned laminates," Composites Part A: Applied Science and Manufacturing, vol. 38, no. 2, pp. 244-251, 2007.

[177] A. P. Mouritz, "Compression properties of z-pinned composite laminates," Composites Science and Technology, vol. 67, no. 15-16, pp. 3110-3120, 2007.

[178] C. A. Steeves and N. A. Fleck, "In-plane properties of composite laminates with through-thickness pin reinforcement," International Journal of Solids and Structures, vol. 43, no. 10, pp. 31973212, 2006.

[179] A. Kessler and A. K. Bledzki, "Low velocity impact behavior of glass/epoxy cross-ply laminates with different fiber treatments," Polymer Composites, vol. 20, no. 2, pp. 269-278, 1999.

[180] A. K. Bledzki, J. Gassan, and A. Kessler, "Loss energy of composite materials. Part II: impact loading," Journal of Testing and Evaluation, vol. 27, no. 1, pp. 36-41, 1999.

[181] A. Kessler and A. Bledzki, "Correlation between interphaserelevant tests and the impact-damage resistance of glass/epoxy laminates with different fibre surface treatments," Composites Science and Technology, vol. 60, no. 1, pp. 125-130, 2000.

[182] Y. Hirai, H. Hamada, and J.-K. Kim, "Impact response of woven glass-fabric composites - I. Effect of fibre surface treatment," Composites Science and Technology, vol. 58, no. 1, pp. 91-104, 1998.

[183] P. Yeung and L. J. Broutman, "The effect of glass-resin interface strength on the impact strength of fiber reinforced plastics," Polymer Engineering \& Science, vol. 18, no. 2, pp. 62-72, 1978.

[184] A. M. El-Habak, "Effect of impact perforation load on GFRP composites," Composites, vol. 24, no. 4, pp. 341-345, 1993.

[185] J. Kim and Y.-W. Mai, "Effects of interfacial coating and temperature on the fracture behaviours of unidirectional Kevlar and carbon fibre reinforced epoxy resin composites," Journal of Materials Science, vol. 26, no. 17, pp. 4702-4720, 1991. 
[186] B. S. Hayes and J. C. Seferis, "Toughened carbon fiber prepregs using combined liquid and preformed rubber materials," Polymer Engineering and Science, vol. 41, no. 2, pp. 170-177, 2001.

[187] K. Jang, W.-J. Cho, and C.-S. Ha, "Influence of processing method on the fracture toughness of thermoplastic-modified, carbon-fiber-reinforced epoxy composites," Composites Science and Technology, vol. 59, no. 7, pp. 995-1001, 1999.

[188] B. S. Hayes and J. C. Seferis, "Modification of thermosetting resins and composites through preformed polymer particles: A review," Polymer Composites, vol. 22, no. 4, pp. 451-467, 2001.

[189] B. S. Hayes, E. N. Gilbert, and J. C. Seferis, "Modification of epoxy based carbon fiber prepregs through combined liquid and preformed rubber materials," in Proceedings of the 45th International SAMPE Symposium and Exhibition, Long Beach, Calif, USA, May 2000.

[190] B. S. Hayes, J. C. Seferis, E. Anderson, and J. Angal, "Novel elastomeric modification of epoxy/carbon fiber composite systems," Journal of Advanced Materials, vol. 28, no. 4, pp. 20-25, 1997.

[191] J. Kim and R. E. Robertson, "Preparation of Poly(butylene terephthalate)-toughened epoxies," in Toughened Plastics I, C. K. Riew, Ed., vol. 233 of Advances in Chemistry, pp. 427-449, American Chemical Society, Washington, DC, USA, 1993.

[192] R. A. Pearson, "Toughening epoxies using rigid thermoplastic particles," in Toughened Plastics I, C. K. Riew and A. J. Kinloch, Eds., vol. 233 of Advances in Chemistry, pp. 405-425, American Chemical Society, Washington, DC, USA, 1993.

[193] H.-J. Sue, R. E. Jones, and E. I. Garcia-Meitin, "Fracture behaviour of model toughened composites under Mode I and Mode II delaminations," Journal of Materials Science, vol. 28, no. 23, pp. 6381-6391, 1993.

[194] N. Odagiri, T. Muraki, and K. Tobukuro, "Toughness improved high performance torayca prepreg T800H/3900 series," in Proceedings of the in 33rd International SAMPE Symposium, 1988.

[195] N. Odagiri, H. Kishi, and T. Nakae, “T800H/3900-2 toughened epoxy prepreg system: Toughening concept and mechanism," in Proceedings of the 6th Technical Conference on American Society for Composites, 1991.

[196] M. R. Groleau, Y.-B. Shi, A. F. Yee, J. L. Bertram, H. J. Sue, and P. C. Yang, "Mode II fracture of composites interlayered with nylon particles," Composites Science and Technology, vol. 56, no. 11, pp. 1223-1240, 1996.

[197] M. Hoisington, J. C. Seferis, and R. S. Schaffnit, "Prepreg toughening concepts for high performance composites," in Proceedings of the 22nd International SAMPE Technical Conference, pp. 446-454, November 1990.

[198] M. A. Hoisington and J. C. Seferis, "Model multilayer structured composites," S.A.M.P.E. quarterly, vol. 24, no. 2, pp. 10-20, 1993.

[199] P. T. McGrail and S. D. Jenkins, "Some aspects of interlayer toughening in thermosetting composites," Polymer, vol. 33, no. 1, pp. 360-361, 1992.

[200] F. Gao, G. Jiao, Z. Lu, and R. Ning, "Mode II delamination and damage resistance of carbon/epoxy composite laminates interleaved with thermoplastic particles," Journal of Composite Materials, vol. 41, no. 1, pp. 111-123, 2007.

[201] F. Gao, G. Jiao, Y. Gao, R. Ning, and Z. Lu, "Damage resistance and damage tolerance of HT3/QY8911 with thermoplastic particle interlayers," Acta Materiae Compositae Sinica, vol. 23, no. 1, pp. 167-172, 2006.
[202] M. Ali and S. C. Joshi, "Impact damage resistance of CFRP prepreg laminates with dispersed CSP particles into ply interfaces," International Journal of Damage Mechanics, vol. 21, no. 8, pp. 1106-1127, 2012.

[203] M. Ali and S. C. Joshi, "Damage evolution in glass/epoxy composites engineered using core-shell microparticles under impact loading," Journal of Materials Science, vol. 48, no. 24, pp. 8354-8367, 2013.

[204] M. Ali, A. Tan, and S. C. Joshi, “Tailoring of bonded composite scarf joint interface for impact damage mitigation and stiffness compatibility," Plastics, Rubber and Composites, vol. 45, no. 2, pp. 43-49, 2016. 

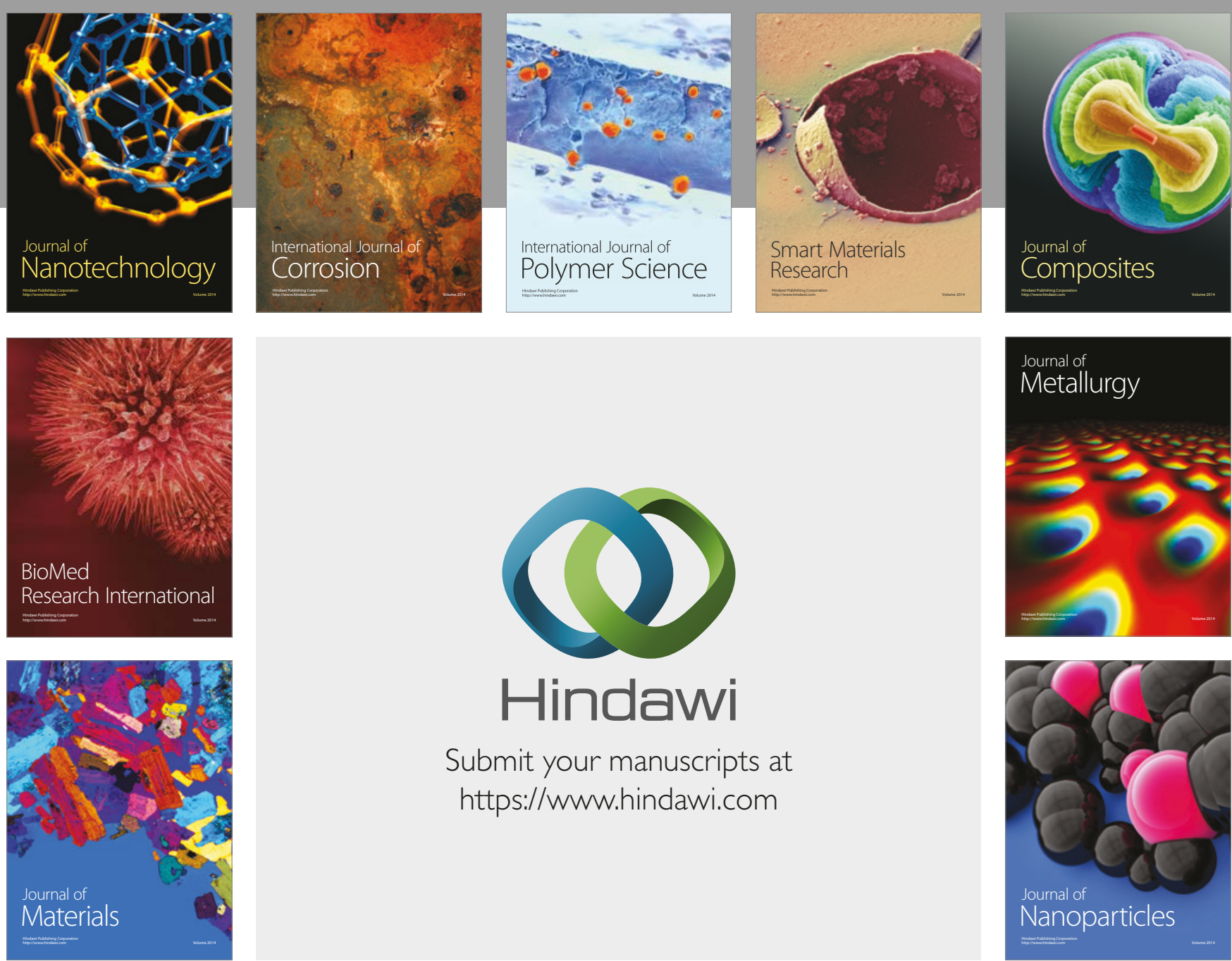

\section{Hindawi}

Submit your manuscripts at

https://www.hindawi.com
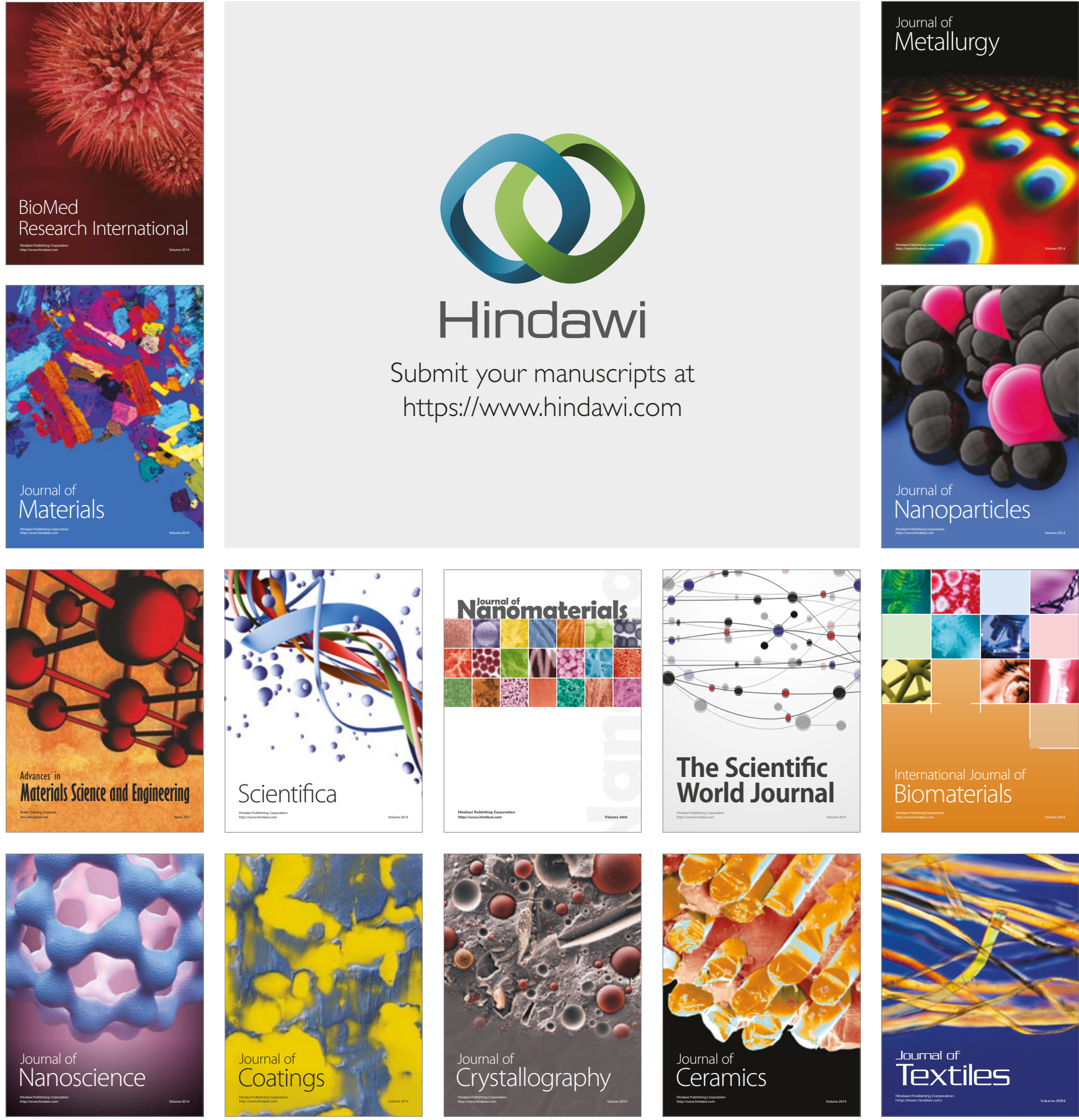

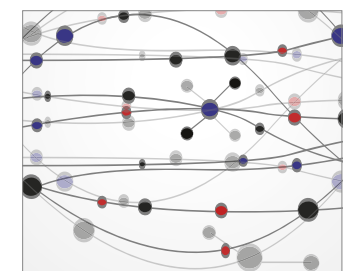

The Scientific World Journal
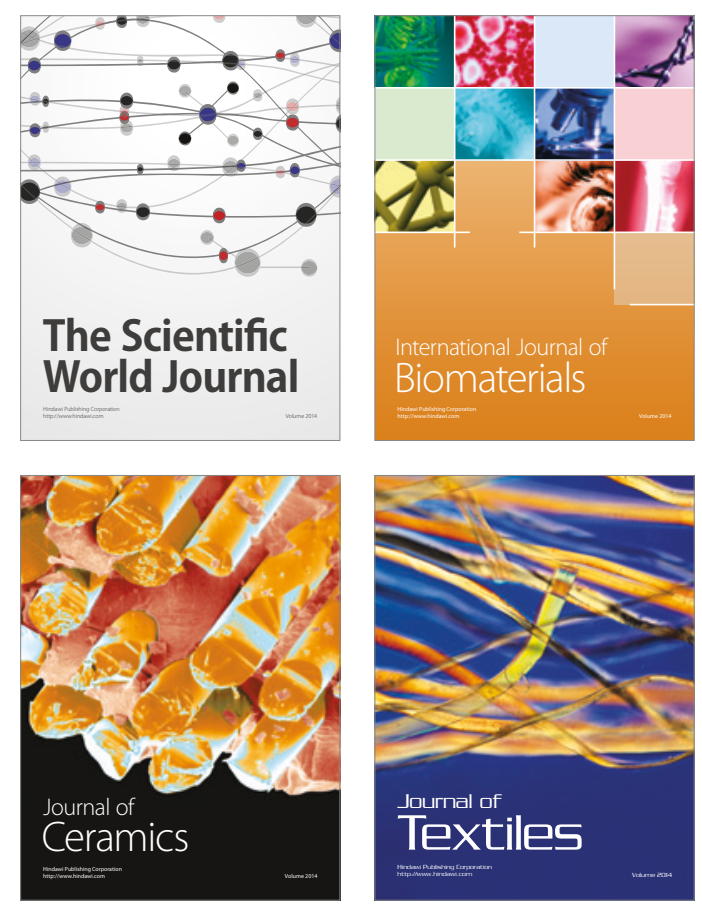